Cover. Recovery of fractured rock matrix incubated within a borehole at the Naval Air Warfare Center Trenton for a period of one year to allow colonization by the indigenous microbial community. 


\section{Microbial Mineralization of $c$ is-Dichloroethene and Vinyl Chloride as a Component of Natural Attenuation of Chloroethene Contaminants under Conditions Identified in the Field as Anoxic}

By Paul M. Bradley

Prepared in cooperation with the Strategic Environmental Research and Development Program

Scientific Investigations Report 2012-5032 


\section{U.S. Department of the Interior \\ KEN SALAZAR, Secretary \\ U.S. Geological Survey \\ Marcia K. McNutt, Director}

\section{U.S. Geological Survey, Reston, Virginia: 2012}

For more information on the USGS — the Federal source for science about the Earth, its natural and living resources, natural hazards, and the environment, visit http://www.usgs.gov or call 1-888-ASK-USGS.

For an overview of USGS information products, including maps, imagery, and publications, visit http://www.usgs.gov/pubprod

To order this and other USGS information products, visit http://store.usgs.gov

Any use of trade, product, or firm names is for descriptive purposes only and does not imply endorsement by the U.S. Government.

Although this report is in the public domain, permission must be secured from the individual copyright owners to reproduce any copyrighted materials contained within this report.

Suggested citation:

Bradley, P.M., 2012, Microbial mineralization of cis-dichloroethene and vinyl chloride as a component of natural attenuation of chloroethene contaminants under conditions identified in the field as anoxic: U.S. Geological Survey Scientific Investigations Report 2012-5032, 30 p. 


\section{Contents}

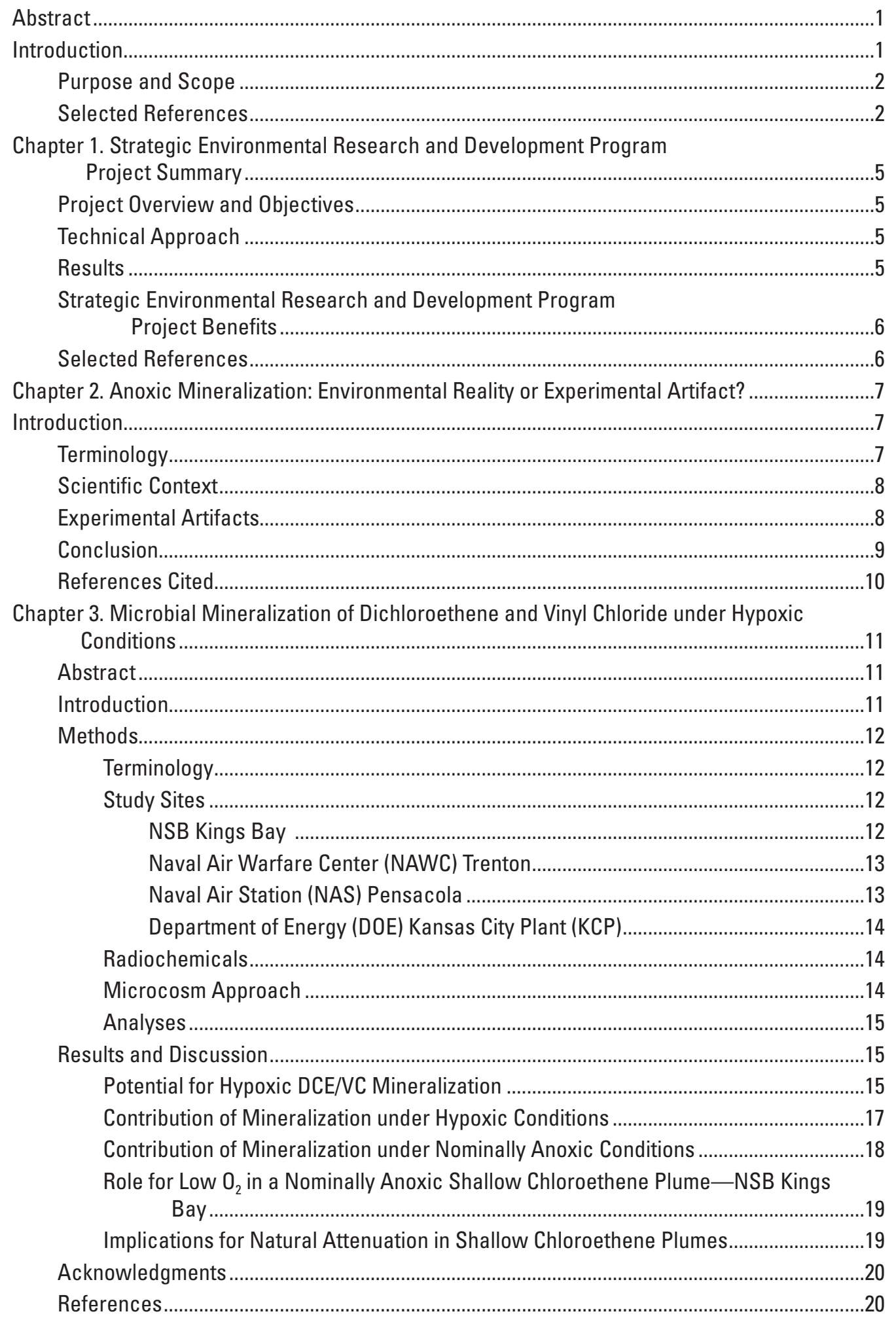


Chapter 4. Reinterpreting the Importance of Oxygen-Based Biodegredation in

Chloroethene-Contaminated Groundwater .......................................................................23

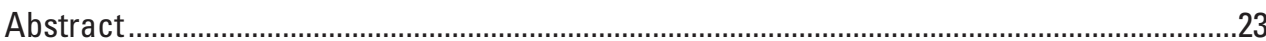

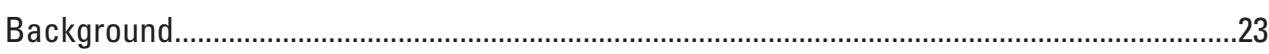

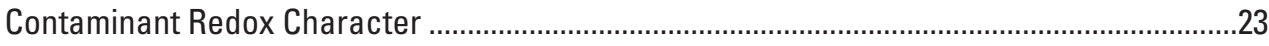

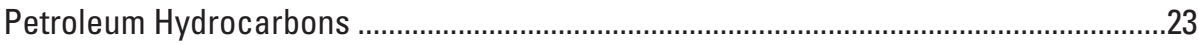

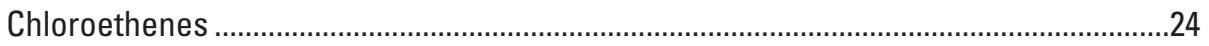

Interpreting the Contribution of Oxygen to Biodegradation ..................................................25

Electron-Donor-Based Biodegradation of Petroleum Hydrocarbons.............................25

Electron-Acceptor-Based Biodegradation of Chloroethenes..........................................26

Electron-Donor-Based Biodegradation of DCE and VC................................................26

Proposed Framework for Chloroethene Natural Attenuation Redox Interpretation ................27

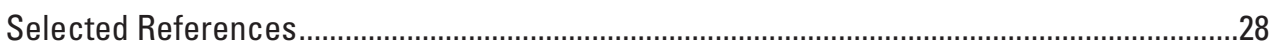

Appendix 1: Project Publications ………………..........................................................................

\section{Figures}

1. Schematic presentation of the various terms used to describe environmental oxygen and redox conditions in subsurface environments.

2. Map of NSB Kings Bay site with monitoring well network ...

3. Graph showing variation in dissolved concentrations of $\mathrm{VC}$ and $\mathrm{O}_{2}$ observed in USGS 4 and USGS 8 during 2002-2007.

4. Graph showing change in rate of mineralization of $\left[1,2-{ }^{-14} \mathrm{C}\right] \mathrm{VC}$ to ${ }^{14} \mathrm{CO}_{2}$ and ${ }^{14} \mathrm{CH}_{4}$ as a function of initial substrate concentration in triplicate DOE KCP BR microcosms incubated under hypoxic and anoxic conditions..

5. Graphs showing mean percentage recovery of ${ }^{14} \mathrm{C}$-products in microcosm treatmentsamended with $\left[1,2-{ }^{-14} \mathrm{C}\right]$ VC or $\left[1,2-{ }^{14} \mathrm{C}\right]$ cis-DCE at an initial substrate concentration of $10 \mu \mathrm{M}$.

6. Diagram showing that during biodegradation, contaminants can serve as electron donors or as electron acceptors for microbial respiration, a process that yields energy for metabolism and growth

7. Diagram of modified framework for assessing mechanisms of chloroethene natural attenuation in groundwater, including the potential role of aerobic mineralization in the absence of detectable dissolved oxygen. 


\section{Tables}

1. VC mineralization kinetics under hypoxic and anoxic conditions ..................................16

2. cis-DCE mineralization kinetics under hypoxic and anoxic conditions............................17

\section{Conversion Factors}

Inch/Pound to SI

\begin{tabular}{lcll}
\hline & Multiply & By & To obtain \\
\hline inch (in.) & Length & \\
foot (ft) & 2.54 & centimeter (cm) \\
\hline
\end{tabular}

SI to Inch/Pound

\begin{tabular}{|c|c|c|}
\hline Multiply & By & To obtain \\
\hline \multicolumn{3}{|c|}{ Length } \\
\hline meter (m) & 3.281 & foot $(\mathrm{ft})$ \\
\hline meter $(\mathrm{m})$ & 1.094 & yard (yd) \\
\hline \multicolumn{3}{|c|}{ Volume } \\
\hline liter (L) & 1.057 & quart (qt) \\
\hline liter $(\mathrm{L})$ & 0.2642 & gallon (gal) \\
\hline \multicolumn{3}{|c|}{ Mass } \\
\hline $\operatorname{gram}(\mathrm{g})$ & 0.03527 & ounce, avoirdupois (oz) \\
\hline \multicolumn{3}{|c|}{ Rate } \\
\hline meter per year $(\mathrm{m} / \mathrm{y})$ & 3.281 & foot per year (ft/y) \\
\hline
\end{tabular}

Temperature in degrees Celsius $\left({ }^{\circ} \mathrm{C}\right)$ may be converted to degrees Fahrenheit $\left({ }^{\circ} \mathrm{F}\right)$ as follows:

${ }^{\circ} \mathrm{F}=\left(1.8 x^{\circ} \mathrm{C}\right)+32$ 


\section{Abbreviations}

\begin{tabular}{|c|c|}
\hline g & gram \\
\hline h & hour \\
\hline $\mathrm{m}$ & meter \\
\hline $\mathrm{g} / \mathrm{L}$ & gram per liter \\
\hline $\mathrm{mg} / \mathrm{L}$ & milligram per liter \\
\hline $\mathrm{mL}$ & milliliter \\
\hline $\mathrm{mL} / \mathrm{min}$ & milliliter per minute \\
\hline$\mu \mathrm{Ci} / \mu \mathrm{mole}$ & microcurie per micromole \\
\hline$\mu \mathrm{g} / \mathrm{L}$ & microgram per liter \\
\hline$\mu \mathrm{M}$ & micromolar; micromole(s) per liter \\
\hline$\mu \mathrm{M} / \mathrm{L}$ & micromole per liter \\
\hline$n M$ & nanomolar; nanomole(s) per liter \\
\hline nmole(s) & nanomole(s) \\
\hline DCE & dichloroethene \\
\hline DO & dissolved oxygen \\
\hline DOD & Department of Defense \\
\hline DOE & Department of Energy \\
\hline GC/RD & gas chromatography/radiometric detection \\
\hline KCP & Kansas City Plant \\
\hline MDL & method detection limit \\
\hline NAWC & Naval Air Warfare Center \\
\hline NAS & Naval Air Station \\
\hline NSB & Naval Submarine Base \\
\hline PCE & perchloroethene; tetrachloroethene \\
\hline PSI & pound per square inch \\
\hline SD & standard deviation \\
\hline SERDP & $\begin{array}{l}\text { Strategic Environmental Research and } \\
\text { Development Program }\end{array}$ \\
\hline TCE & trichloroethene \\
\hline VC & vinyl chloride; chloroethene \\
\hline WWTP & wastewater treatment plant \\
\hline
\end{tabular}




\title{
Microbial Mineralization of cis-Dichloroethene and Vinyl Chloride as a Component of Natural Attenuation of Chloroethene Contaminants under Conditions Identified in the Field as Anoxic
}

\author{
By Paul M. Bradley
}

\section{Abstract}

Chlororespiration is a key component of remediation at many chloroethene-contaminated sites. In some instances, limited accumulation of reductive dechlorination daughter products may suggest that natural attenuation is not adequate for site remediation. This conclusion is justified when evidence for parent compound (tetrachloroethene, PCE, or trichloroethene, TCE) degradation is lacking. For many chloroethene-contaminated shallow aquifer systems, however, non-conservative losses of the parent compounds are clear but the mass balance between parent compound attenuation and accumulation of reductive dechlorination daughter products is incomplete. Incomplete mass balance indicates a failure to account for important contaminant attenuation mechanisms, and is consistent with contaminant degradation to non-diagnostic mineralization products. An ongoing technical debate over the potential for mineralization of dichloroethene (DCE) and vinyl chloride (VC) to $\mathrm{CO}_{2}$ in the complete absence of diatomic oxygen has largely obscured the importance of microbial DCE/VC mineralization at dissolved oxygen (DO) concentrations below the current field standard ( $\mathrm{DO}<0.1-0.5$ milligrams per liter) for nominally anoxic conditions. This study demonstrates that oxygen-based microbial mineralization of DCE and VC can be substantial under field conditions that are frequently characterized as "anoxic." Because mischaracterization of operant contaminant biodegradation processes can lead to expensive and ineffective remedial actions, a modified framework for assessing the potential importance of oxygen during chloroethene biodegradation was developed.

\section{Introduction}

Field methods for identifying and quantifying dichloroethene (DCE), vinyl chloride (VC), ethene and ethane are well established. Consequently, assessing the production and accumulation of these reductive dechlorination products and ethane within nominally "anoxic," chloroethene-contaminated, groundwater plumes has become an operationally convenient method for investigating the extent and efficiency of chloroethene biodegradation in situ. Owing in large part to the historical success of this approach, the in situ absence of ethene, ethane and, in some cases, $\mathrm{VC}$ under nominally anoxic conditions has been increasingly interpreted as evidence of a lack of complete chloroethene degradation, a so-called degradative "stall."

The preceding conclusion assumes that reductive dechlorination is the only significant mechanism of microbial degradation of DCE and $\mathrm{VC}$ under field conditions characterized as anoxic. Equally plausible explanations include transformation of DCE, $\mathrm{VC}$, ethene and ethane to $\mathrm{CO}_{2}$ (or other innocuous products) in the strict absence of molecular oxygen or at dissolved oxygen concentrations below the current field standard for nominally anoxic conditions (typically, 0.1 to $0.5 \mathrm{mg} / \mathrm{L}$ dissolved oxygen). Previous reports that describe the accumulation of chloride ion far in excess of the accumulation of DCE, VC, ethene, and ethane (Weidemeier and others, 1999a, b) indicate that relying solely on accumulation of these reductive dechlorination products as a measure of the efficiency of natural attenuation under nominally anoxic field conditions may be problematic .

The field observations just described illustrate a critically important question that must be addressed in assessing the efficacy of natural attenuation as a component of in situ chloroethene remediation: Is the potential for microbial DCE/ VC mineralization important under field conditions nominally identified as anoxic? Nominally anoxic field conditions include strict oxygen-free environments, as well as low oxygen environments in which dissolved oxygen (DO) concentrations fall below the typical field detection limit for $\mathrm{DO}$ of 0.1 to $0.5 \mathrm{mg} / \mathrm{L}$.

Numerous investigations have demonstrated efficient degradation of DCE and VC to mineralization products at DO concentrations below the field standard for nominally anoxic conditions (Bradley and Chapelle, 1996, 1997, 1998, 1999, 2000, 2007; Bradley and others, 1998a, b, c; Gossett, 2010; Singh and others, 2004). The of establishment of DO concentrations less than the analytical detection limits of 
0.01 to $0.02 \mathrm{mg} / \mathrm{L}$ without the use of chemical reductants, as employed by this author, does not completely rule out the theoretical contribution of trace oxygen. The mineralization of DCE and VC in the studies just mentioned, however, clearly occurred at DO concentrations well below the 0.1 - to $0.5-\mathrm{mg} / \mathrm{L}$ field standard for nominally anoxic conditions (Bradley and Chapelle, 1996, 1997, 1998, 1999, 2000, 2007; Bradley and others, 1998a, b, c). Likewise, Gossett (2010) independently confirmed that mineralization of $\mathrm{VC}$ can be significant at DO concentrations well below the 0.1 - to $0.5-\mathrm{mg} / \mathrm{L}$ field standard for nominally anoxic conditions and provided compelling quantitative evidence that aerobic mechanisms can contribute to $\mathrm{VC}$ biodegradation at $\mathrm{DO}$ concentrations at least as low as $0.01 \mathrm{mg} / \mathrm{L}$. In light of these earlier findings, the relative importance of $\mathrm{O}_{2}$ at $\mathrm{DO}$ concentrations below the currently accepted 0.1 to $0.5 \mathrm{mg} / \mathrm{L}$ field standard for anoxic conditions and the potential contribution of aerobic processes to chloroethene attenuation within nominally anoxic plumes was investigated in this study.

This investigation of chloroethene-contaminant biodegradation mechanisms and associated effects on the quality of water resources was conducted by the USGS in cooperation with the Strategic Environmental Research and Development Program (SERDP) of the U.S. Department of Defense and its federal partners, the U.S. Environmental Protection Agency and the U.S. Department of Energy. This investigation benefits Federal interests by aligning with four of the six science directions of the USGS Science Strategy (U.S. Geological Survey, 2007): (1) Understanding Ecosystems and Predicting Ecosystem Change: Ensuring the Nation's Economic and Environmental Future; (2) Energy and Minerals for America's Future: Providing a Scientific Foundation for Resource Security, Environmental Health, Economic Vitality, and Land Management; (3) The Role of Environment and Wildlife in Human Health: A System that Identifies Environmental Risk to Public Health in America; and (4) A Water Census of the United States: Quantifying, Forecasting, and Securing Freshwater for America's Future.

\section{Purpose and Scope}

The purpose of this report is to present the results of a SERDP funded investigation of DCE and VC biodegradation in groundwater and surface water under field conditions that are characterized as anoxic. Chapter 1 provides SERDPspecified project information. Chapter 2 discusses the role that ambiguous scientific terminology has played in the ongoing controversy over the environmental relevance of chloroethene mineralization under nominally anoxic conditions. Chapter 3 presents evidence that oxygen-based microbial mineralization of DCE and VC can be substantial under field conditions that are frequently characterized as anoxic. Because mischaracterization of operant contaminant biodegradation processes can lead to expensive and ineffective remedial actions, Chapter 4 presents a modified framework for assessing the potential importance of oxygen during chloroethene biodegradation. Chapters 2, 3, and 4 have been published previously as journal articles in Ground Water Monitoring \& Remediation. They are reprinted here with permission of the National Ground Water Association. The definitive versions of these articles are available at www.Blackwell-Synergy.com.

\section{Selected References}

Bradley, P.M., and Chapelle, F.H., 1996, Anaerobic mineralization of vinyl chloride in $\mathrm{Fe}$ (III)-reducing, aquifer sediments: Environmental Science and Technology, v. 30, no. 6, p. 2084-2086.

Bradley, P.M., and Chapelle, F.H., 1997, Kinetics of DCE and VC mineralization under methanogenic and Fe (III)-reducing conditions: Environmental Science and Technology, v. 31, no. 9, p. 2692-2696.

Bradley, P.M., and Chapelle, F.H., 1998, Microbial Mineralization of VC and DCE Under Different Terminal Electron Accepting Conditions* 1: Anaerobe, v. 4, no. 2, p. 81-87.

Bradley, P.M., and Chapelle, F.H., 1999, Role for acetotrophic methanogens in methanogenic biodegradation of vinyl chloride: Environmental Science and Technology, v. 33, no. 19 , p. 3473-3476.

Bradley, P.M., and Chapelle, F.H., 2000, Acetogenic microbial degradation of vinyl chloride: Environmental Science and Technology, v. 34, no. 13, p. 2761-2763.

Bradley, P.M., and Chapelle, F.H., 2007, Accumulation of dechlorination daughter products: A valid metric of chloroethene biodegradation: Remediation Journal, v. 17, no. 4, p. 7-22.

Bradley, P.M., Chapelle, F.H., and Lovley, D.R., 1998a, Humic acids as electron acceptors for anaerobic microbial oxidation of vinyl chloride and dichloroethene: Applied and Environmental Microbiology v. 64, no. 8, p. 3102.

Bradley, P.M., Chapelle, F.H., and Wilson, J.T., 1998b, Field and laboratory evidence for intrinsic biodegradation of vinyl chloride contamination in a Fe (III)-reducing aquifer: Journal of Contaminant Hydrology, v. 31, no. 1-2, p. 111-127.

Bradley, P.M., Landmeyer, J.E., and Dinicola, R.S., 1998c, Anaerobic oxidation of $\left[1,2-{ }^{14} \mathrm{C}\right]$ dichloroethene under Mn (IV)-reducing conditions: Applied and Environmental Microbiology, v. 64, no. 4, p. 1560.

Gossett, J.M., 2010, Sustained aerobic oxidation of vinyl chloride at low oxygen concentrations: Environmental Science and Technology, v. 44, no. 4, p. 1405-11. 
Wiedemeier, T.H., Rifai H.S., Newell C.J., and Wilson, J.T., 1999a, Evaluating natural attenuation, chap. 7 of Wiedemeier, T.H., Rifai, H.S., Newell, C.J., and Wilson, J.T., eds., Natural Attenuation of Fuels and Chlorinated Solvents in the Subsurface: New York, John Wiley and Sons, p. $298-360$.

Wiedemeier, T.H., Rifai H.S., Newell C.J., and Wilson, J.T., 1999b, Intrinsic bioremediation of chlorinated contaminants, chap. 6 of Wiedemeier, T.H., Rifai, H.S., Newell, C.J., and Wilson, J.T., eds., Natural Attenuation of Fuels and Chlorinated Solvents in the Subsurface: New York, John Wiley and Sons, p. 241-297.
Singh, Harvinder, Löffler, F.E., and Fathepure, B.Z., 2004, Aerobic biodegradation of vinyl chloride by a highly enriched mixed culture: Biodegradation, v. 15 , no. 3 , p. 197-204.

U.S. Geological Survey, 2007, Facing tomorrow's challenges-U.S. Geological Survey science in the decade 2007-2017: U.S. Geological Survey Circular 1309, 70 p. 



\title{
Chapter 1. Strategic Environmental Research and Development Program Project Summary
}

\author{
By P.M. Bradley
}

\section{Project Overview and Objectives}

The research described herein addresses the technical needs outlined in ERSON-07-04 (SERDP, 2007). The research approach directly addresses the first two priorities identified in ERSON-07-04 and indirectly addresses the third:

- Determine abiotic and biotic mechanisms of cis-DCE and/or VC degradation under either aerobic or anaerobic conditions,

- Develop a better understanding of the various degradation pathways and reaction kinetics for cis-DCE and/or $\mathrm{VC}$, such that obtaining a mass balance is possible, and

- Determine the relative significance of the various degradation mechanisms for $c i s$-DCE and/or VC under field conditions.

This research assessed the working hypothesis that the measured accumulation of reductive dechlorination daughter products is a poor indicator of cis-DCE and VC degradation under the relatively oxidized, nominally anoxic conditions that characterize many shallow groundwater and surface-water sites. This study seeks to clarify whether the aerobic mineralization of DCE and VC represents an important mechanism of chloroethene attenuation at in situ DO concentrations below the current field standard for nominally anoxic conditions, or if the trace DO concentrations observed in the field represent a metabolically insignificant residual of aerobic activity in the adjacent oxic zone.

\section{Technical Approach}

$\mathrm{A}^{14} \mathrm{C}$-radiotracer microcosm approach allowed direct assessment of the potential for microbial mineralization of cis-DCE and VC and the relative mass balance between parent compound disappearance and the accumulation of reductive dechlorination and/or mineralization products. Nominally anoxic field conditions include strict oxygen-free environments, as well as low oxygen environments in which dissolved oxygen (DO) concentrations fall below the typical field detection limit for DO of 0.1 to $0.5 \mathrm{mg} / \mathrm{L}$. Thus, the potential for mineralization of $\left[1,2-{ }^{14} \mathrm{C}\right]$ cis-DCE and $[1,2-$ $\left.{ }^{14} \mathrm{C}\right] \mathrm{VC}$ was assessed in this study under hypoxic conditions and in the absence of detectable DO. The relative contribution of aerobic processes to DCE and $\mathrm{VC}$ degradation under low oxygen conditions (DO concentration $<0.1 \mathrm{mg} / \mathrm{L}$ ) was explored in groundwater and surface-water sediment from four chloroethene contaminated sites. This was accomplished by comparing the extent and kinetics of DCE and VC mineralization in microcosms initially containing $0.1 \mathrm{mg} / \mathrm{L} \mathrm{DO}$ (hypoxic treatments) with that observed in microcosms having no detectable DO (nominally anoxic treatments with DO concentrations less than the analytical detection limit of $0.01 \mathrm{mg} / \mathrm{L}$ ). Field evidence supporting a potential role for DO (at concentrations below $0.1 \mathrm{mg} / \mathrm{L}$ ) is presented for the apparent non-conservative attenuation of VC in the shallow surficial aquifer at Naval Submarine Base (NSB) Kings Bay, where accumulations of the potential chlororespiration degradates, ethene, and ethane, do not equal the apparent loss of $\mathrm{VC}$ along the groundwater flowpath.

\section{Results}

The mineralization of ${ }^{14} \mathrm{C}$-radiolabled vinyl chloride $\left(\left[1,2-{ }^{14} \mathrm{C}\right] \mathrm{VC}\right)$ and cis-dichloroethene $\left(\left[1,2-{ }^{14} \mathrm{C}\right]\right.$ cis-DCE $)$ under hypoxic and nominally anoxic conditions was examined in chloroethene-exposed sediments from two groundwater and two surface-water sites (Chapter 3). The results indicate significant VC and DCE mineralization under hypoxic conditions, defined as having initial dissolved oxygen (DO) concentration of about $0.1 \mathrm{mg} / \mathrm{L}$. All sample treatments exhibited pseudofirst-order kinetics for DCE and VC mineralization over an extended range of substrate concentrations. First-order rates for $\mathrm{VC}$ mineralization were approximately 1 to 2 orders of magnitude higher in hypoxic groundwater sediment treatments and at least three times higher in hypoxic surface-water sediment treatments than in the respective anoxic treatments. For $\mathrm{VC}$, oxygen-linked processes accounted for 65 to 85 percent of mineralization at DO concentrations below $0.1 \mathrm{mg} / \mathrm{L}$, and ${ }^{14} \mathrm{CO}_{2}$ was the only degradation product observed in VC treatments under hypoxic conditions. Because the lower detection limit for DO concentrations measured in the field is typically 0.1 to $0.5 \mathrm{mg} / \mathrm{L}$, these results indicate that oxygen-linked VC and DCE biodegradation can be significant under field conditions that appear anoxic. Furthermore, because rates of VC mineralization exceeded rates of DCE mineralization under hypoxic conditions, DCE accumulation without concomitant accumulation of VC may not be evidence of a DCE degradative "stall" in chloroethene plumes. Significantly, mineralization of $\mathrm{VC}$ above the level that could reasonably be attributed to residual DO contamination was also observed in several nominally anoxic (DO minimum detection limit $=0.01 \mathrm{mg} / \mathrm{L}$ ) microcosm treatments. A modified redox framework for assessing the role and potential importance of 
oxygen-to-chloroethene biodegradation was formulated based on the results (Chapter 4). This investigation provides an improved understanding of the mechanisms and environmental relevance of, and conditions conducive to, the microbial degradation of DCE and VC to products not typically associated with reductive dechlorination.

\section{Strategic Environmental Research and Development Program Benefits}

The degradation of DCE and VC at low concentrations of dissolved oxygen appears to be a key contaminant attenuation mechanism (Chapter 3 herein; Gossett, 2010), and failure to recognize this process can have substantial consequences. Existing protocols for assessing in situ biodegradation of chloroethene contaminants focus on chlororespiration. Accordingly, the accumulations of reductive dechlorination products like DCE, VC, ethene, and by extension, ethane are unequivocal evidence of ongoing reductive dechlorination biodegradation. Aerobic microbial processes can degrade all of these compounds to $\mathrm{CO}_{2}$. Consequently, unless the role of oxygen is recognized, the associated lack of reductive dechlorination products will be interpreted incorrectly as evidence of incomplete degradation, a degradative "stall." Mischaracterization of operant contaminant biodegradation processes can lead to expensive and ineffective remedial actions.

\section{Selected References}

Strategic Environmental Restoration and Defense Program, 2007, Investigation of cis-dichloroethene and vinyl chloride degradation mechanisms and environmental relevance: ERSON-07-04. http://www.serdp.org/FundingOpportunities/SERDP-Solicitations/ 


\title{
Chapter 2. Anoxic Mineralization: Environmental Reality or Experimental Artifact?
}

\author{
By P.M. Bradley, F.H. Chapelle, and F.E. Löffler
}

\section{Introduction}

The environmental sciences combine field investigation with laboratory experimentation in order to understand complex ecological relationships. While field application is the ultimate goal, isolation of specific environmental interactions is often impractical under field conditions. Laboratory studies allow the isolation of relevant microorganisms and specific biogeochemical interactions, but also introduce experimental biases, which can complicate data interpretation and raise concerns about the environmental relevance of the results.

The ongoing debate over the role of anoxic microbial mineralization processes in the bioremediation of environmental contaminants like vinyl chloride (VC), illustrates the challenge assessing the environmental relevance of laboratory results. The potential for reductive dechlorination of $\mathrm{VC}$ to ethene in highly-reducing environments is well established. Field methods for quantifying ethene are available, and the degradation processes that lead to accumulation of ethene can be evaluated in situ. In contrast, reliable field methods for assessing the degradation of $\mathrm{VC}$ to mineralized products (e.g. $\mathrm{CO}_{2}$ and inorganic chloride) are not currently available. Instead, our understanding of anoxic microbial VC mineralization is based primarily on laboratory observations. As a result, the environmental relevance of the process remains controversial.

Judging the environmental relevance of laboratory research requires an understanding of both the in situ and the laboratory experimental conditions and, consequently, is particularly susceptible to miscommunication. The following is a discussion of the roles that ambiguities in the scientific terminology and incomplete communication of laboratory experimental approaches, conditions and associated biases may play in the ongoing controversy over the environmental relevance of laboratory observations, like anoxic mineralization of VC. For technical discussions of chloroethene biodegradation, the reader is referred to reviews on the processes and environmental applications of microbial dechlorination, in general (e.g. Häggblom and Bossert 2003), and on chlorinated ethene mineralization (e.g. Bradley 2003) and the diversity of dechlorinating bacteria (e.g. Löffler et al. 2003), in specific.

\section{Terminology}

Several terms are employed by different scientific sub-disciplines to describe oxygen-limited and oxygen-free environmental conditions. The fact that many of these terms have well-established but distinctly different meanings for individual sub-disciplines is a fundamental problem. To illustrate, some of the frequently employed terms are discussed along with their common usages. Greek derived terms are presented with literal or strict "scientific" translations. It should be noted that each term has, at some point, been employed in the scientific literature as a synonym for "oxygen-free." Figure 1 depicts the relationship between the different terms and usages.

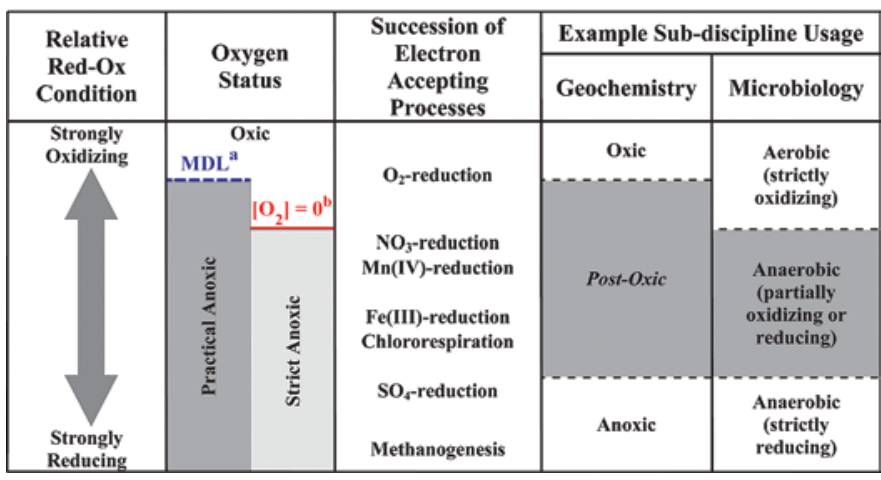

Figure 1. Schematic presentation of the various terms used to describe environmental oxygen and redox conditions in subsurface environments. Dashed lines indicate imprecisely defined boundaries between categories.

ANOXIC -is a Greek-derived term composed of the prefix "an" which means "not" or "without" and the root "oxic" which, in a modern scientific context, refers to "oxygen." Anoxic is conceptually the most straightforward of the many terms used to describe "oxygen-free" environments and, theoretically, indicates the complete absence of oxygen. In light of the difficulty assessing low oxygen concentrations while inhabiting a $21 \%$ by volume oxygen atmosphere, however, groundwater has been considered anoxic at dissolved oxygen concentrations below $0.1-0.5 \mathrm{mg} / \mathrm{L}$. Although meticulous sampling technique can improve the field detection limit for dissolved oxygen, the fact remains that anoxia is operationally defined by practical limitations on field oxygen measurements.

The term, "anoxic," does not identify the alternative terminal electron accepting processes that may be occurring in the absence of oxygen. Nevertheless, certain environmental sub-disciplines (e.g., geochemistry) have reserved this term for those highly reducing conditions under which sulfidogenesis and methanogenesis provide tacit evidence for the absence of 
oxygen. For these sub-disciplines, a variety of additional terms [e.g. post-oxic ("after" oxygen), dysoxic ("bad" oxygen), sub-oxic ("below" oxygen), and hypoxic ("low" or "deficient" oxygen)] have been coined to refer to the poorly defined range between verifiably "oxic" conditions and detectably sulfidogenic/methanogenic conditions.

ANAEROBIC -is another Greek-derived term composed of the prefix " $a$ " that means "without" and the prefix "aero" which means "air." The root, "bic" is an adjective form of "bios" and refers to "life" or "living." In a strict sense, anaerobic refers to life or activity in the "absence of air." Thus, the potential for confusion arises immediately, because the term anaerobic is used almost exclusively to refer to an absence of free oxygen but not to an absence of nitrogen, despite the fact that air is $71 \%$ nitrogen by volume.

This confusion is exacerbated by the fact that "anaerobic" and particularly the combined term, "strictly anaerobic," are used by many microbiologists to refer exclusively to highlyreducing homoacetogenic, sulfidogenic (sulfate-reducing) and/or methanogenic conditions, but not to the more oxidized nitrate-reducing, manganese-reducing or iron-reducing conditions, which also occur in the "absence of air".

MICROAEROPHILIC - is a Greek-based term composed of the prefix "micro" meaning "little," the prefix "aero" which means "air," and the root "philic" which means "loving." Microaerophilic is an adjective describing those microorganisms that require some oxygen for growth and metabolic activity but that do not function well, or at all, at ambient (i.e., $21 \%$ by volume) oxygen concentrations. Thus, "microaerophilic" is an imprecise term indicating that the oxygen concentration is below $21 \%$ but not zero.

REDUCING -refers to environmental conditions that favor a decrease in the oxidation state of reactive chemical species. For the succession of terminal electron accepting processes presented in Figure 1, those conditions on the oxygenreducing end would be considered strongly oxidizing while conditions on the methanogenic end would be considered strongly reducing. Reducing is a relative term that is meaningful only in contrast to the term oxidizing. For example, methanogenic conditions are substantially more reducing than are iron-reducing conditions, even though both occur in the absence of oxygen.

This partial list illustrates the latitude in terminology and, consequently, the substantial potential for miscommunication when discussing anoxic conditions. To minimize miscommunication, the oxygen and/or redox conditions that are under investigation must be described explicitly.

\section{Scientific Context}

In experimental science, the investigative approach and study conditions depend inordinately on the question being asked. Thus, understanding the scientific context of experimental studies is crucial to the interpretation of results. In the case of anoxic microbial mineralization of $\mathrm{VC}$, understanding the scientific context begins with the meaning of the term "anoxic."

Historically, anaerobic microbiology has focused on the microorganisms and associated metabolic pathways that operate in the strict absence of oxygen. Consequently, many of these studies have been conducted under highly reducing conditions to ensure the strict absence of oxygen. If a study site is predominated by highly reducing conditions, then laboratory experimental procedures that establish such conditions are appropriate when assessing contaminant biodegradation.

However, for sites where oxygen is not detectable but extant redox conditions include the relatively oxidized, anoxic electron accepting processes (e.g., nitrate-reducing, manganese-reducing, and iron-reducing), laboratory experimental conditions must address the degradation potential associated with these relatively oxidized electron acceptors. In this context, a reasonable laboratory approach would ensure that dissolved oxygen concentrations are below detection while preserving the indigenous potential for nitrate-, manganese-, and iron-reduction.

\section{Experimental Artifacts}

Experimental artifacts are inherent in all scientific investigations, but are a matter of particular concern when laboratory results are applied to the field. Because research publications highlight the intent of experimental procedures, the associated experimental biases and their implications may go unrecognized. To illustrate this issue with respect to anoxic VC mineralization, two important experimental artifacts are considered.

The risk associated with oxygen contamination of nominally "oxygen-free" systems is well known and a primary focus of traditional "anaerobic" microbiological methods. For many environmental contaminants, including VC, rates of biodegradation are often orders of magnitude greater in the presence of oxygen than in its absence. Moreover, oxygenbased processes are more likely to result in complete degradation to innocuous mineralization products like $\mathrm{CO}_{2}$, whereas biodegradation under highly reducing conditions may lead to accumulation of toxic intermediates. In general, the presence of oxygen under ostensibly "oxygen-free" conditions can lead to an overestimation of the potential for in situ bioremediation and an unacceptable underestimation of the environmental risk associated with groundwater and surface-water contaminants.

Because of the well-known biases associated with oxygen contamination, many efforts to assess microbial activity under anoxic conditions alter the redox character of the experimental environment to the extent that the presence of oxygen is unlikely in the extreme. Common alterations include the preparation of experimental cultures and microcosms in anaerobic chambers that contain a reducing atmosphere (i.e., hydrogen up to $5 \%$ by volume), the use of organic and/or inorganic reductants (e.g., sulfide, cysteine, dithiothreitol, titanium citrate) to promote reducing conditions, and the strict use 
of the Hungate technique for media preparation and culture manipulation. To visually confirm reducing conditions, redox indicators like resazurin (changes color from pink to clear below $-110 \mathrm{mV}$ ) are often added to the culture medium. The use of such strict anaerobic techniques has been fundamental to the study of reductive dechlorination processes, development of stable dechlorinating consortia and pure cultures, ongoing characterization of Dehalococcoides biology, and field applications where native or bioaugmented Dehalococcoides bacteria have been used to detoxify chlorinated ethene contamination.

However, such strict anaerobic techniques have impacts beyond the establishment of oxygen-free conditions. The hydrogen, that is present in the "anaerobic mixed gases" used in glove boxes, is a powerful reductant and an excellent electron donor for many microbially-mediated terminal electron accepting processes, including respiratory reductive dechlorination (chlororespiration). In addition to the intended elimination of oxygen, incorporation of organic (e.g., cysteine, dithiothreitol, titanium citrate) and/or inorganic (e.g., sulfide) reductants can deplete the pool of relatively oxidized anoxic terminal electron acceptors. Although the redox indicator resazurin is useful to visualize strongly reducing conditions, it is not an appropriate indicator for relatively oxidized, anoxic redox conditions.

If the potential for contaminant biodegradation under the entire range of anoxic terminal electron accepting conditions is to be investigated, then the use of highly reducing, anaerobic techniques introduces an unacceptable, but poorly recognized, experimental artifact. Such conditions are likely to inhibit or even prohibit the contribution of a number of terminal electron accepting processes like nitrate-, manganese-, and iron-reduction, which occur in anoxic but relatively oxidizing environments. Indeed, the predominance in anaerobic microbiology of procedures that establish highly reducing conditions introduces enrichment biases against microorganisms that prefer or require more oxidizing redox conditions and may have contributed to the relatively late isolation of Mn(IV)and Fe(III)-reducing organisms. Thus, when assessing the quantitative importance of anoxic microbial mineralization processes, it is critical that laboratory investigations include relatively oxidizing, anoxic redox conditions.

Bradley and Chapelle originally investigated the potential for anoxic biodegradation of $\mathrm{VC}$ in a shallow aquifer that was characterized by visible iron staining and predominately iron-reducing redox conditions. Initial efforts to prepare nominally anoxic sediment microcosms using chemical reductants resulted in highly-reducing sulfidogenic conditions, termination of iron reduction and immediate concerns that such an approach significantly altered the microbial ecology, pathways and products of contaminant degradation that may be important under field conditions. Subsequently, microcosms were prepared by purging oxygen to below detection (oxygen analytical detection limit of $10 \mu \mathrm{M}$ in the headspace, less than $10 \mu \mathrm{g} / \mathrm{L}$ dissolved oxygen), but avoiding further changes to the sediment redox environment. The mineralization of $\left[1,2-{ }^{14} \mathrm{C}\right]$ VC to ${ }^{14} \mathrm{CO}_{2}$ that was observed under $\mathrm{Mn}(\mathrm{IV})$ - and $\mathrm{Fe}(\mathrm{III})$-reducing conditions, raised the possibility that anoxic microbial mineralization of $\mathrm{VC}$ may be an environmentally relevant mechanism and indicated that the potential for this process should be assessed under relatively oxidized, anoxic conditions.

\section{Conclusion}

Laboratory and field studies have established the environmental relevance of the reductive dechlorination process for remediating chlorinated ethene-contaminated sites. This scientific understanding has enabled "intelligent design" engineering of subsurface environments and improved our ability to successfully remediate field sites. However, redox conditions at chlorinated-ethene contaminated sites can range from highly-reducing anoxic to relatively-oxidized anoxic to oxic. Consequently, researchers and practitioners should recognize the biases introduced by establishing highly reducing conditions and should continue to explore those alternative detoxification pathways that may predominate under relatively oxidized anoxic conditions. Ultimately, comprehensive knowledge of all metabolic pathways affecting chlorinated ethenes is desirable and will provide practitioners additional remediation options. To ensure the transfer of knowledge, however, the results of specific scientific studies must be accurately communicated using explicitly defined language, because "anoxic" is different from "reducing", and the distinction has important consequences for assessing and remediating chlorinated ethene-contaminated sites.

Reprinted from Ground Water Monitoring \& Remediation with permission of the National Ground Water Association.

Reprinted from Ground Water Monitoring \& Remediation with permission of the National Ground Water Association.v

The definitive version of this article is available at $w w w$. Blackwell-Synergy.com 


\section{References Cited}

Bradley, P. M. (2003) History and ecology of chloroethene biodegradation: A review. Bioremediation Journal, 7, 81-109.

Häggblom, M.M. and I.D. Bossert. 2003. Dehalogenation: Microbial Processes and Environmental Applications. Häggblom, M.M. and I.D. Bossert (eds.). Kluwer Acedemic Publishers, Boston, Massachussetts. 501 p.

Löffler, F.E., J.R. Cole, K.M. Ritalahti, and J.M. Tiedje. Diversity of dechlorinating bacteria. Pp. 53-88. In Dehalogenation: Microbial Processes and Environmental Applications. Häggblom, M.M. and I.D. Bossert (eds.). Kluwer Acedemic Publishers, Boston, Massachussetts.
Biographical Sketches

Paul M. Bradley, Ph.D., corresponding author, research ecologist, South Carolina Water Science Center, U.S. Geological Survey, Columbia, SC 29210; (803) 750-6125; fax: (803) 750-6181; pbradley@usgs.gov.

Francis H. Chapelle, Ph.D., research hydrologist, South Carolina Water Science Center, U.S. Geological Survey, Columbia, SC 29210; (803) 750-6116; fax: (803) 750-6181; chapelle@usgs.gov.

Frank E. Löffler, Ph.D., Carlton Wilder Associate Professor of Environmental Engineering; Georgia Institute of Technology; School of Civil \& Environmental Engineering and School of Biology, 311 Ferst Drive, ES\&T, Room 3228, Atlanta, GA 30332-0512; (404) 894-0279; fax: (404) 8948266; frank.loeffler@ce.gatech.edu. 


\title{
Chapter 3. Microbial Mineralization of Dichloroethene and Vinyl Chloride under Hypoxic Conditions
}

\author{
By Paul M. Bradley, and Francis H. Chapelle
}

\begin{abstract}
Mineralization of ${ }^{14} \mathrm{C}$-radiolabled vinyl chloride ([1,2$\left.\left.{ }^{14} \mathrm{C}\right] \mathrm{VC}\right)$ and cis-dichloroethene $\left(\left[1,2-{ }^{14} \mathrm{C}\right]\right.$ cis-DCE) under hypoxic (initial dissolved oxygen (DO) concentrations about $0.1 \mathrm{mg} / \mathrm{L}$ ) and nominally anoxic (DO minimum detection limit $=0.01 \mathrm{mg} / \mathrm{L}$ ) was examined in chloroethene-exposed sediments from two groundwater and two surface water sites. The results show significant $\mathrm{VC}$ and DCE mineralization under hypoxic conditions. All sample treatments exhibited pseudofirst-order kinetics for DCE and VC mineralization over an extended range of substrate concentrations. First-order rates for VC mineralization were approximately 1-2 orders of magnitude higher in hypoxic groundwater sediment treatments and at least three times higher in hypoxic surface water sediment treatments than in the respective anoxic treatments. For VC, oxygen-linked processes accounted for $65-85 \%$ of mineralization at $\mathrm{DO}$ concentrations below $0.1 \mathrm{mg} / \mathrm{L}$ and ${ }^{14} \mathrm{CO}_{2}$ was the only degradation product observed in $\mathrm{VC}$ treatments under hypoxic conditions. Because the lower detection limit for DO concentrations measured in the field is typically $0.1-0.5 \mathrm{mg} / \mathrm{L}$, these results indicate that oxygen-linked VC and DCE biodegradation can be significant under field conditions that appear anoxic. Furthermore, because rates of $\mathrm{VC}$ mineralization exceeded rates of DCE mineralization under hypoxic conditions, DCE accumulation without concomitant accumulation of VC may not be evidence of a DCE degradative "stall" in chloroethene plumes. Significantly, mineralization of VC above the level that could reasonably be attributed to residual DO contamination was also observed in several nominally anoxic (DO minimum detection limit $=0.01 \mathrm{mg} / \mathrm{L}$ ) microcosm treatments.
\end{abstract}

\section{Introduction}

Prospects for complete natural attenuation of chloroethene-contaminated groundwater are complicated by the considerable variation in redox character in the chloroethene contaminant class. The polychlorinated tetrachloroethene (PCE) and trichloroethene (TCE) compounds are potent electron acceptors, effectively degraded by reductive processes like chlororespiration, and generally recalcitrant to oxidative degradation mechanisms (Vogel et al. 1987; Bradley 2003). Dichloroethene (DCE) and vinyl chloride (VC) are much less oxidized, and complete dechlorination via chlororespiration is often inefficient under natural attenuation conditions due to inactive or insufficient populations of compound-specific dechlorinators (e.g., VC chlororespirers), electron-donor competition with other indigenous microbial communities, and a range of other potentially limiting conditions (Vogel et al. 1987; Bradley 2003). By contrast, complete dechlorination of DCE and VC via aerobic degradation processes is highly efficient (Bradley and Chapelle 1998b, 1998a, 2000b; Coleman et al. 2002a, 2002b; Bradley 2003; Singh et al. 2004; Gossett 2010).

Owing to this range in chloroethene redox character, it has long been recognized that a sequential change in groundwater redox conditions along the contaminant flowpath from reducing conditions in the PCE/TCE-dominated source area to oxidizing, preferably oxic, conditions in the down-gradient, DCE/VC-dominated zones provides the best opportunity for efficient and complete dechlorination of chloroethene contaminated groundwater (Bradley 2003, 2000). Notable naturally occurring examples are the recognized potential for sequential anaerobic/aerobic biodegradation at the oxic fringe of anoxic chloroethene plumes and at the interface between anoxic groundwater and oxic surface water in wetlands and stream hyporheic zones (Bradley 2003, 2000). Aerobic degradation mechanisms are often considered unimportant within anaerobically active chloroethene plumes. Chlororespiration is considered the most important mechanism of contaminant biodegradation in these settings. In current practice chlororespiration is emphasized under nominally anoxic conditions to the extent that in situ accumulation of DCE without concomitant accumulation of reduced, chlorinated daughter products like $\mathrm{VC}$ or non-chlorinated daughter products like ethene (and by extension ethane) is considered prima facie evidence of incomplete degradation, a so-called degradative stall (Bradley and Chapelle 2007).

An ongoing technical debate over the potential for mineralization of DCE and $\mathrm{VC}$ to $\mathrm{CO}_{2}$ in the complete absence of diatomic oxygen has largely obscured the practical and critically important question, is the potential for microbial DCE/VC mineralization, whatever the metabolic process, significant at DO concentrations below the current field standard (DO $<0.1-0.5 \mathrm{mg} / \mathrm{L}$ ) for nominally anoxic conditions? Numerous investigations have demonstrated efficient degradation of DCE and VC to mineralization products at DO concentrations below the field standard for nominally anoxic conditions (Bradley and Chapelle 1996, 1997, 1998b, 1999a, 1999b, 2000a; Bradley et al. 1998a; Bradley et al. 1998b; Bradley et al. 1998c; Singh et al. 2004; Gossett 2010). While the approach (establishment of DO concentrations less than 
the analytical detection limits of $0.01-0.02 \mathrm{mg} / \mathrm{L}$ without the use of chemical reductants), which was employed by the current authors to assess the potential for DCE/VC mineralization under nominally anoxic conditions without undue alteration of the intrinsic redox conditions, does not completely rule out the theoretical contribution of trace oxygen, the mineralization of DCE and VC in these studies clearly occurred at DO concentrations well below the $0.1-0.5 \mathrm{mg} / \mathrm{L}$ field standard for nominally "anoxic" conditions (Bradley and Chapelle 1996, 1997, 1998b, 1999a, 1999b, 2000a; Bradley et al. 1998a; Bradley et al. 1998b; Bradley et al. 1998c). Likewise, Gossett (2010) independently confirmed that mineralization of $\mathrm{VC}$ can be significant at DO concentrations well below the $0.1-0.5 \mathrm{mg} / \mathrm{L}$ field standard for nominally anoxic conditions and provided compelling quantitative evidence that aerobic mechanisms can contribute to $\mathrm{VC}$ biodegradation at $\mathrm{DO}$ concentrations at least as low as $0.01 \mathrm{mg} / \mathrm{L}$. In light of these reports, the relative importance of $\mathrm{O}_{2}$ at $\mathrm{DO}$ concentrations below the currently accepted $0.1-0.5 \mathrm{mg} / \mathrm{L}$ field standard for anoxic conditions and the potential contribution of aerobic processes to chloroethene attenuation within nominally anoxic plumes merit further investigation.

This study seeks to clarify whether aerobic mineralization of DCE and VC represents an important mechanism of chloroethene attenuation at in situ DO concentrations below the current field standard for nominally anoxic conditions or if the trace DO concentrations observed in the field represent a metabolically insignificant residual of aerobic activity in the adjacent oxic zone. The relative contribution of aerobic processes to DCE and VC degradation under low (DO concentrations < $0.1 \mathrm{mg} / \mathrm{L}$ ) oxygen conditions is explored in groundwater and surface water sediment from four chloroethene contaminated sites, by comparing the extent and kinetics of DCE and VC mineralization in microcosm treatments initially containing $0.1 \mathrm{mg} / \mathrm{L}$ DO with that observed in treatments with no detectable DO (DO concentrations $<0.01 \mathrm{mg} / \mathrm{L}$ ). Field evidence supporting a potential role for DO (at concentrations below $0.1 \mathrm{mg} / \mathrm{L}$ ) is presented for the apparent non-conservative attenuation of $\mathrm{VC}$ in the shallow surficial aquifer at Naval Submarine Base (NSB) Kings Bay, where accumulations of the potential chlororespiration degradates, ethene and ethane, do not equal the apparent loss of VC along the groundwater flowpath.

\section{Methods}

\section{Terminology}

The term, hypoxic, is used for treatments established with initial DO concentrations of $0.1 \mathrm{mg} / \mathrm{L}$. The term, nominally anoxic, is used for treatments established without detectable DO; DO concentrations less than the $0.01 \mathrm{mg} / \mathrm{L}$ minimum detection limit for the gas chromatographic method employed in this study. Given the uncertainty in $\mathrm{O}_{2}$ concentrations at the analytical detection limit, however, the theoretical role that $\mathrm{O}_{2}$ may have played in anoxic treatments was assessed conservatively by assuming a theoretical maximum mass of $\mathrm{O}_{2}$ equivalent to double the minimum detection limit. This maximum theoretical mass was compared to the calculated $\mathrm{O}_{2}$ requirement if the mineralization of ${ }^{14} \mathrm{C}-\mathrm{DCE}$ or ${ }^{14} \mathrm{C}$-VC observed in the anoxic treatments was coupled to aerobic processes.

\section{Study Sites}

\section{NSB Kings Bay}

The contaminant distribution, and geology of the Department of Defense (DOD) site at the NSB Kings Bay near Kings Bay, Georgia have been described in detail elsewhere (Chapelle and Bradley 1998; Chapelle et al. 2005). The sediments underlying the site are of marginal marine origin and record a prograding shoreline of Pliocene-Pleistocene age. The hydrology of the Kings Bay site reflects the geology. The sands exposed at land surface are relatively permeable and absorb all or most of the rain that falls on the site. In more than 11 years of monitoring, surface-water runoff from the site has never been observed. During precipitation events, water saturates the sandy soil and percolates downward into the subsurface. NSB Kings Bay aquifer samples were collected from a layer of organic-rich sands and clays near KBA-11-13A (NSB King GW1) and USGS 8 (NSB King GW2) at depths of 3-4 m (Figure 2). The organic content of the collected sediments was estimated based on loss on ignition to be $1.6 \pm 0.2 \%$ of dry weight for both locations. Nominally anoxic microcosms prepared in this study with Kings Bay sediments were actively Fe(III)-reducing.

A groundwater-monitoring network, which includes three transects of 4-7 wells oriented perpendicular to groundwater flow, was emplaced in 1998 using direct push technology (Figure 2). The groundwater velocity at the site was estimated to range between 15-30 m y-1 (Chapelle and Bradley 1998). The Kings Bay site has been monitored quarterly since 1998 in order to document the behavior of a chloroethene plume subsequent to source-area removal (Chapelle and Bradley 1998; Chapelle et al. 2005). For simplicity, groundwater data for USGS 4 and USGS 8 (located approximately $50 \mathrm{~m}$ down gradient) are presented here. Each monitoring well was pumped with a peristaltic pump at a rate of about $500 \mathrm{~mL} /$ $\mathrm{min}$, and the temperature, $\mathrm{pH}$, and conductivity continuously monitored until they achieved stability. Concentrations of DO were measured in the field using colorimetric methods (minimum detection limit $=0.05 \mathrm{mg} / \mathrm{L}$; Chemetrics, Inc). The predominant redox process in the contaminant plume between USGS 4 and USGS 8 transects appears to be Fe(III)-reduction (Chapelle and Bradley 1998; Chapelle et al. 2005). However, trace DO concentrations have been detected periodically along the groundwater flowpath, raising the possibility that 


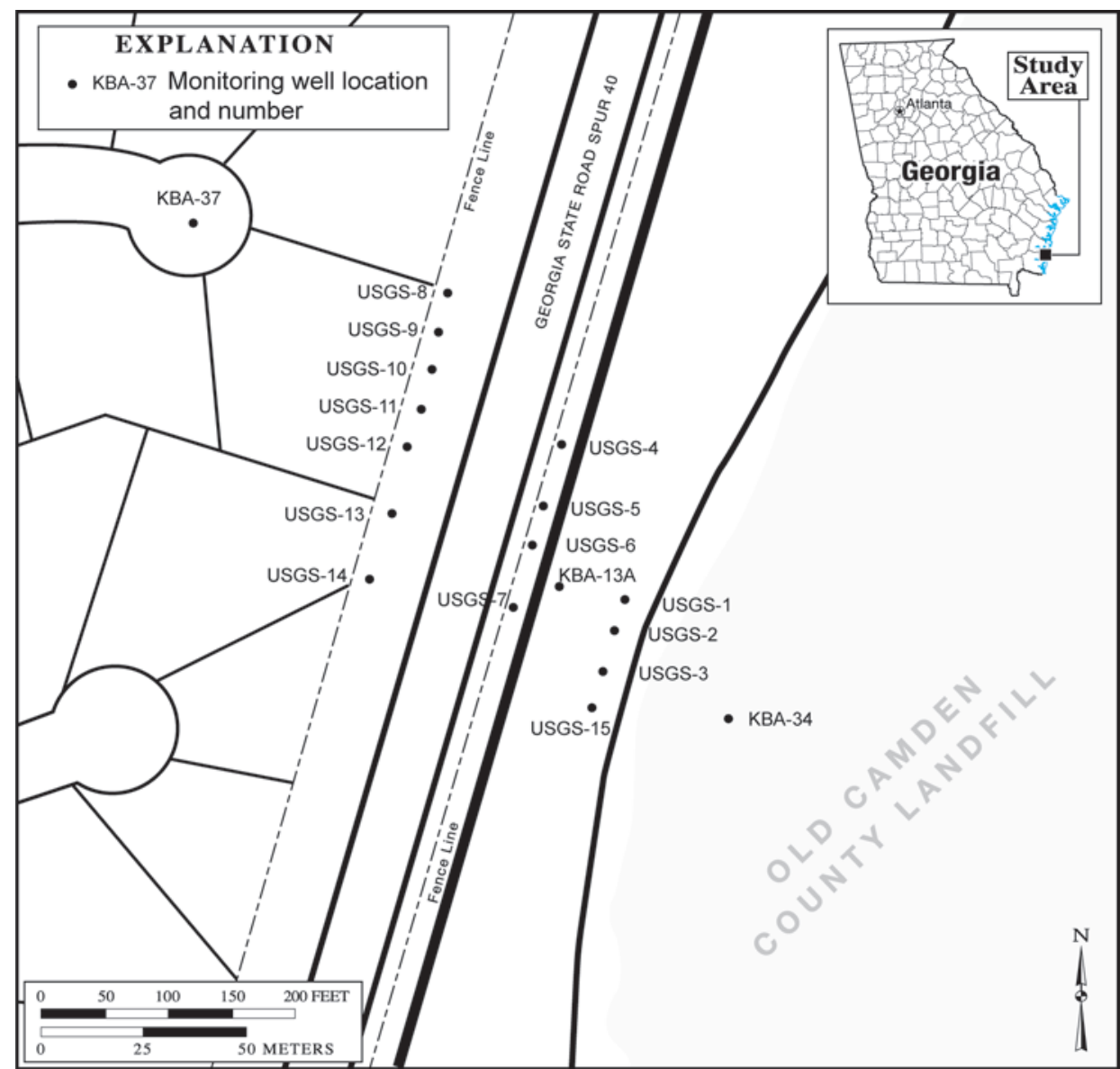

Figure 2. Map of NSB Kings Bay site with monitoring well network. Chloroethene plume extends from the source area near KBA-34 northwest toward KBA-37.

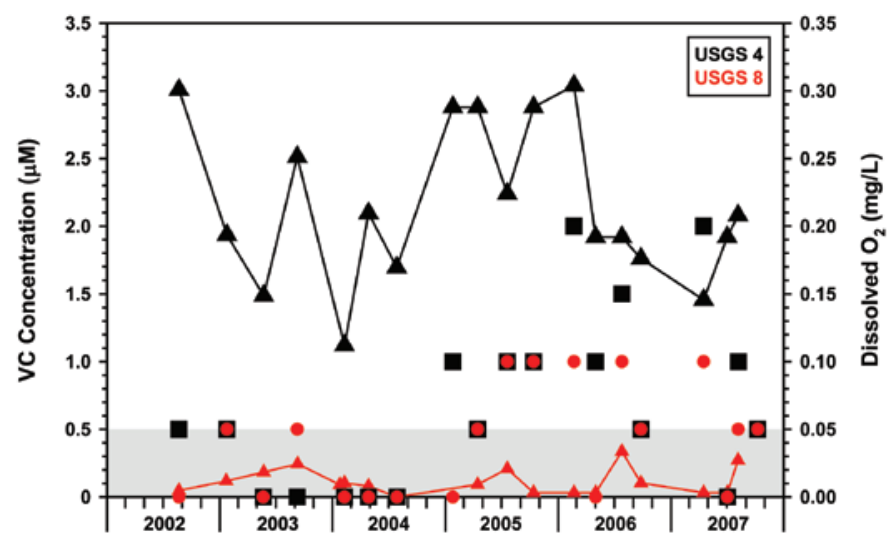

Figure 3. Variation in dissolved concentrations of $\mathrm{VC}\left(\mu \mathrm{M}\right.$; triangles) and $\mathrm{O}_{2}(\mathrm{mg} / \mathrm{L}$; squares) observed in USGS 4 (black symbols) and USGS 8 (red symbols) during 2002-2007. Top of gray area indicates the dissolved oxygen minimum detection limit (MDL $=0.05 \mathrm{mg} / \mathrm{L})$. Ethene was detectected infrequently and only at the $\mathrm{MDL}(=0.3 \mu \mathrm{M})$. Ethane was not detected $(\mathrm{MDL}=0.3 \mu \mathrm{M})$ precipitation-driven fluxes of $\mathrm{O}_{2}$ to the chloroethene plume may be significant (Figure 3).

\section{Naval Air Warfare Center (NAWC) Trenton}

The contaminant distribution and geology of the DOD NAWC Trenton site near West Trenton, New Jersey have been described elsewhere (Bradley et al 2009). The site is a decommissioned military jet engine testing facility that is underlain by fractured, Triassic-age mudstone shales and sandstones. Samples of aquifer matrix consisted of depth-specific core material that was crushed and emplaced within a packed interval at a depth of $42 \mathrm{~m}$ below land surface for a period of one year to allow colonization by the indigenous microbial community. The organic content of the collected core material was estimated based on loss on ignition to be less than $0.1 \pm 0.0 \%$ of dry weight. Nominal anoxic microcosms prepared in this study with NAWC Trenton core material were actively methanogenic.

\section{Naval Air Station (NAS) Pensacola}

The contaminant distribution and geology of the DOD NAS Pensacola site near Pensacola, Florida has been described elsewhere (Bradley et al. 2007b). The NAS Pensacola wastewater treatment plant (WWTP) has been 
processing industrial solvents since 1971. Historical use of unlined drying beds to dewater WWTP sludge resulted in areally extensive chlorinated solvent contamination of the shallow groundwater system, which extends downgradient toward Pensacola Bay. Surface-water sediment was collected in Pensacola Bay down gradient from the NAS Pensacola site. Pensacola Bay sediments (NAS Pens Bay) were saline. The organic content of the collected sediments was estimated based on loss on ignition to be $0.3 \pm 0.0 \%$ of dry weight. Nominal anoxic microcosms prepared in this study with Pensacola bay sediments were actively $\mathrm{SO}_{4}$ reducing.

\section{Department of Energy (DOE) Kansas City Plant (KCP)}

Surface-water sediments were collected from two stream sites [Blue River (DOE KCP BR); Indian Creek (DOE KCP IC)] at the DOE KCP, located within the Bannister Federal Complex in Kansas City, Missouri. The Federal Complex is bordered by the Blue River on the east and by its tributary, Indian Creek, on the south. Mixed chlorinated solvent plumes, containing primarily TCE and the reductive-degradation products 1,2-DCE and VC, exist in the shallow groundwater system in the northeastern and southern portions of the KCP and extend toward the Blue River and Indian Creek, respectively. The organic contents of the sediments collected from DOE KCP BR and DOE KP IC were estimated based on loss on ignition to be $3.7 \pm 0.2$ and $2.7 \pm 0.3 \%$ of dry weight, respectively. Nominal anoxic microcosms prepared in this study with DOE KCP sediments were actively methanogenic.

\section{Radiochemicals}

The potential for chloroethene biodegradation was investigated using uniformly labeled $\left[1,2-{ }^{14} \mathrm{C}\right]$ cis-DCE $(4 \mu \mathrm{Ci} /$ $\mu$ mole; Moravek Biochemicals, Brea, California) and [1,2$\left.{ }^{14} \mathrm{C}\right] \mathrm{VC}(1.6 \mu \mathrm{Ci} / \mu \mathrm{mole}$; Perkin Elmer Life Sciences, Boston, Massachusetts). Authentic $\mathrm{H}^{14} \mathrm{CO}_{3}^{-}$(Sigma Biochemicals, St. Louis, Missouri), ${ }^{14} \mathrm{CH} 4$ (Perkin Elmer Life Sciences, Boston, Massachusetts), and $\left[1,2-{ }^{14} \mathrm{C}\right]$ ethene (Moravek Biochemicals, Brea, California) were used as radiolabeled standards for calibration and methods development. The radiochemical purities of the ${ }^{14} \mathrm{C}$-substrates were evaluated by direct injection radiometric detection gas chromatography $(\mathrm{GC} / \mathrm{RD})$ and found to be greater than $98 \%$ pure. Accordingly, a threshold for significant recovery of $4 \%$ of theoretical was established. All ${ }^{14} \mathrm{C}$-working solutions were prepared in serum vials containing anoxic water amended with $\mathrm{NaS}_{2} \cdot 9 \mathrm{H}_{2} \mathrm{O}(1 \mathrm{mM})$ to eliminate trace $\mathrm{O}_{2}$.

\section{Microcosm Approach}

Because mineralization products $\left(\mathrm{CO}_{2}\right.$ and $\left.\mathrm{CH}_{4}\right)$ are not uniquely attributable to the biodegradation of chloroethenes or the products associated with chloroethene reduction (ethene and ethane), a ${ }^{14} \mathrm{C}$-radiotracer approach was employed using $\left[1,2-{ }^{14} \mathrm{C}\right]$ cis-DCE and $\left[1,2-{ }^{14} \mathrm{C}\right] \mathrm{VC}$ as substrates.
The production of ${ }^{14} \mathrm{CO}_{2},{ }^{14} \mathrm{CH}_{4},{ }^{14} \mathrm{C}$-ethene, ${ }^{14} \mathrm{C}$-ethane, and ${ }^{14} \mathrm{C}$-VC (in ${ }^{14} \mathrm{C}$-DCE treatment only) were assessed using radiometric detection GC methods developed and employed previously (Bradley and Chapelle 1999a, 1999b, 2002). Methods for the preparation of oxygen-free microcosm studies, the characterization of microcosm redox conditions, and the chromatographic separation and quantification of ${ }^{14} \mathrm{C}$-substrates and ${ }^{14} \mathrm{C}$-products are well-established and have been described in detail elsewhere (Bradley and Chapelle 1999a, 1999b, 2002). Brief descriptions of the general approach to microcosm preparation and analytical methods are as follows.

Sediment microcosms were composed of $10 \mathrm{~mL}$ serum vials with approximately $10 \mathrm{~g}$ of saturated sediment, a total water content of $3 \mathrm{~mL}$, and a headspace volume of approximately $6 \mathrm{~mL}$. Hypoxic treatments were prepared by flushing the microcosm headspace three separate times with $600 \mathrm{~mL}$ of $\mathrm{N}_{2}$ containing 90-100 $\mu$ mole/ $/ \mathrm{L} \mathrm{O}_{2}$ to yield an initial DO concentration of $0.1 \mathrm{mg} / \mathrm{L}$ and an estimated initial microcosm $\mathrm{O}_{2}$ content of $600 \mathrm{nmoles}$. Nominally anoxic treatments were prepared identically, but flushed with ultra-high purity $\mathrm{N}_{2}$ that was first passed through a heated column of reduced copper filings to remove trace oxygen, as described previously (Lovley and Phillips 1986; Bradley et al. 2009). No chemical reductants (cysteine, sulfide, etc) were employed in this study, except in ${ }^{14} \mathrm{C}$-working solutions. Triplicate experimental microcosms, duplicate autoclaved control microcosms, and a single sediment-free container control microcosm were prepared for each sediment treatment. All controls were autoclaved three times for $1 \mathrm{~h}$ at $15 \mathrm{PSI}$ and $121^{\circ} \mathrm{C}$. All microcosms were pre-incubated in the dark for $3 \mathrm{~d}$ prior to the addition of ${ }^{14} \mathrm{C}$-substrates to eliminate trace oxygen from nominal anoxic treatments. All microcosms were incubated in the dark at room temperature (circa $23{ }^{\circ} \mathrm{C}$ ).

On the basis of the results of an earlier study (Bradley and Chapelle 1997), chloroethene mineralization under nominally anoxic conditions can exhibit saturation type (MichaelisMenten) kinetics over the range of environmentally relevant concentrations. The Michaelis-Menten parameters, Vmax and ks, are sensitive to a number of environmental factors and vary according to in situ conditions. Vmax is influenced by microbial biomass, metabolic activity, and the availability of nutrients and substrates that support growth and metabolism. In saturated environments, estimates of ks are particularly sensitive to variations in substrate supply rates resulting from sediment matrix effects and differences in water flow rates. Given these limitations, realistic estimation of in situ kinetic parameters would require exact replication of in situ conditions. Because such estimates are sensitive to a number of environmental factors and because in situ conditions vary significantly over time and from site to site, the current kinetic evaluation is not intended to provide estimates of in situ kinetic parameters, but rather to provide some indication of the potential for hypoxic/ anoxic mineralization of DCE and $\mathrm{VC}$ and a comparison of the general response of mineralization to changes in substrate concentration over a range of sites. Accordingly, the appropriate kinetic model (first-order or saturation Kinetics) was identified 
for the entire range of substrate concentrations examined and a first-order rate constant was estimated for the pseudo-firstorder range of substrate concentrations.

The kinetics of DCE and VC mineralization were assessed under hypoxic and nominally anoxic conditions using the approach of Bradley and Chapelle (1997). Microcosms were incubated under static conditions and initial rates of mineralization to $\mathrm{CO}_{2}\left(\right.$ and $\left.\mathrm{CH}_{4}\right)$ were assessed at $\mathrm{DCE}$ and $\mathrm{VC}$ concentrations ranging from 0.1 to $100 \mu \mathrm{moles} / \mathrm{L}$ (see Figure 4 for example). Hypoxic and anoxic treatments were incubated for approximately 30 days and 100 days, respectively. Initial rates of mineralization were plotted against initial substrate

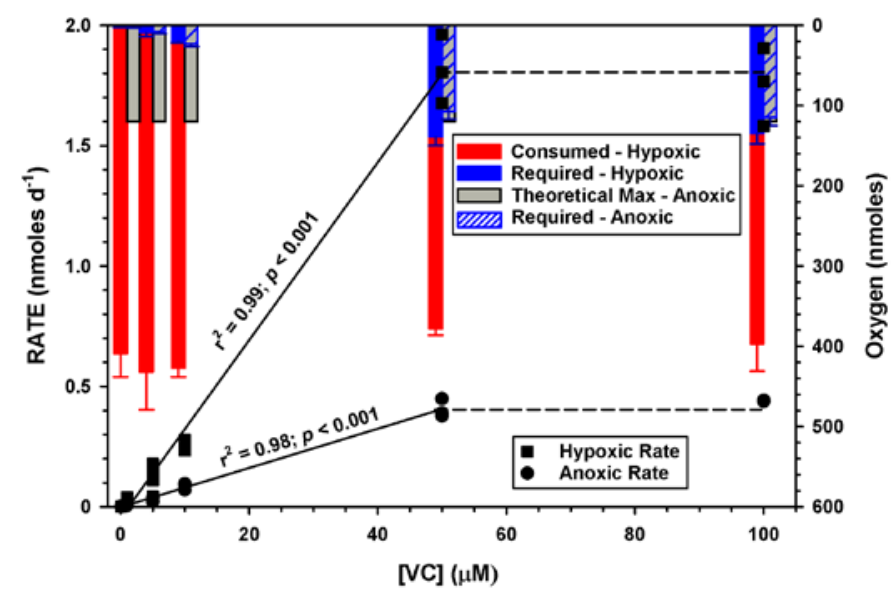

Figure 4. Change in rate $\left(n\right.$ moles $\left.\mathrm{d}^{-1}\right)$ of mineralization of $\left[1,2-{ }^{-14} \mathrm{C}\right] \mathrm{VC}$ to ${ }^{14} \mathrm{CO}_{2}$ and ${ }^{14} \mathrm{CH}_{4}$ as a function of initial substrate concentration $(\mu \mathrm{M})$ in triplicate DOE KCP BR microcosms incubated under hypoxic (black squares) and anoxic (black circles) conditions. The theoretical maximum mass of $\mathrm{O}_{2}$ present (assuming $\mathrm{O}_{2}$ at double the minimum detection limit) and the theoretical $\mathrm{O}_{2}$ requirement if $\mathrm{VC}$ mineralization was coupled to aerobic processes in anoxic treatment microcosms are indicated by the gray and blue hatched bars (mean \pm standard deviation in tripilicate microcosms), respectively.

concentrations to determine the overall kinetics. In this study, most of the treatments exhibited a saturation-type response to increasing substrate concentration. For each, the range of pseudo-first-order behavior was identified and the associated first-order rate constant $\left(\mathrm{d}^{-1}\right)$ was estimated using simple linear regression analysis. The resulting coefficient of determination $\left(\mathrm{r}^{2}\right)$ was used to assess how well the regression model described the variation in the data.

\section{Analyses}

In general, analytical methods were as described previously (Bradley and Chapelle 1999a, 1999b, 2000a; Bradley et al. 2002a, 2002b). Headspace concentrations of $\mathrm{CH}_{4},{ }^{14} \mathrm{CH}_{4}$, $\mathrm{CO}_{2},{ }^{14} \mathrm{CO}_{2}$, ethene, ${ }^{14} \mathrm{C}$-ethene, ethane, ${ }^{14} \mathrm{C}$-ethane, and ${ }^{14} \mathrm{C}$-VC (in ${ }^{14} \mathrm{C}$-DCE treatments only) were monitored using packed column gas chromatography with sequential thermal conductivity detection and radiometric detection. The headspace was only sampled twice to minimize the risk of oxygen contamination. The headspace volume removed during the intermediate sampling event was replaced with pure $\mathrm{N}_{2}$ passed through a heated column of reduced copper filings to remove trace oxygen, as described previously (Lovley and Phillips 1986).

Dissolved phase concentrations of ${ }^{14} \mathrm{C}$-analytes were estimated based on experimentally determined Henry's Partition Coefficients as described previously (Bradley et al. 2001a, 2001b, 2002a). The radiometric detector was calibrated by liquid scintillation counting using $\mathrm{H}^{14} \mathrm{CO}_{3}^{-}$.

Microcosm oxygen contents were determined at the outset in sacrificial replicates and in each treatment microcosm at the end of incubation by thermal conductivity detection gas chromatography using $\mathrm{He}$ as the carrier gas, a 10 - $\mathrm{ft} \times 1 / 8$-in. column packed with 60/80 Molecular Sieve 5A (Supelco, Inc.), and isothermal $\left(50^{\circ} \mathrm{C}\right)$ run conditions. Method calibration and the determination of the analytical detection limit $(0.01 \mathrm{mg} / \mathrm{L}$ dissolved) imposed by the minimum achievable "background" oxygen peak in zero oxygen $\mathrm{N}_{2}$ gas were equivalent to Gossett (2010), excepting the use of a copper reduction column to remove trace $\mathrm{O}_{2}$ from the dilution blanks and the $\mathrm{N}_{2}$ flush gas (Lovley and Phillips 1986; Bradley and Chapelle 2007; Bradley et al. 2009). Headspace samples were acquired from experimental serum bottles using a locking, gastight syringe. Prior to headspace sampling, the syringe and needle were flushed with pure $\mathrm{N}_{2}$ passed through a heated column of reduced copper filings to remove trace oxygen, as described previously (Lovley and Phillips 1986).

The change in $\mathrm{O}_{2}$ content of hypoxic treatments was quantified and compared to the theoretical $\mathrm{O}_{2}$ required to achieve the observed mineralization of ${ }^{14} \mathrm{C}-\mathrm{VC}$ or ${ }^{14} \mathrm{C}$ DCE by aerobic processes, according to Equations 1 and 2, respectively. $\mathrm{No}_{2}$ was detected (minimum detection limit $=0.01 \mathrm{mg} / \mathrm{L}$ dissolved) in any anoxic treatment microcosm during this study. The continued absence of detectable $\mathrm{O}_{2}$ in anoxic sediment-free control microcosms indicated that no $\mathrm{O}_{2}$ was introduced during microcosm sampling. A highly conservative $\mathrm{O}_{2}$ content of 120 nmoles was calculated assuming an anoxic treatment DO concentration equal to double the minimum detection limit and was compared to the theoretical $\mathrm{O}_{2}$ requirement if the mineralization of ${ }^{14} \mathrm{C}-\mathrm{DCE}$ or ${ }^{14} \mathrm{C}-\mathrm{VC}$ observed in the anoxic treatments was coupled to aerobic processes.

$$
\mathrm{C}_{2} \mathrm{H}_{3} \mathrm{Cl}+2.5 \mathrm{O}_{2} \rightarrow 2 \mathrm{CO}_{2}+\mathrm{H}_{2} \mathrm{O}+\mathrm{HCl}
$$

$$
\mathrm{C}_{2} \mathrm{H}_{2} \mathrm{Cl}_{2}+2 \mathrm{O}_{2} \rightarrow 2 \mathrm{CO}_{2}+2 \mathrm{HCl}
$$

\section{Results and Discussion}

\section{Potential for Hypoxic DCE/VC Mineralization}

The importance of aerobic chloroethene mineralization at DO concentrations below the $0.1-0.5 \mathrm{mg} / \mathrm{L}$ field standard for nominally anoxic field conditions was examined in 
Table 1. VC mineralization kinetics under hypoxic (DO Initial $=90-100 \mu \mathrm{g} L-1$ ) and anoxic (MDL $=10 \mu \mathrm{g} \mathrm{L}-1$ ) conditions. See Figure 5 for a final distribution of ${ }^{14} \mathrm{C}$-products in treatments amended with ${ }^{14} \mathrm{C}$-substrate at an initial concentration of $10 \mu \mathrm{M}$.

\begin{tabular}{|c|c|c|c|c|c|c|c|c|c|c|}
\hline \multirow[b]{2}{*}{ Setting } & \multirow[b]{2}{*}{ Site } & \multirow{2}{*}{$\begin{array}{c}\text { VC } \\
\text { range } \\
(\mu \mathrm{g} / \mathrm{L})\end{array}$} & \multirow{2}{*}{$\begin{array}{c}\text { Oxic } \\
\text { status }\end{array}$} & \multirow[b]{2}{*}{ Kinetics } & \multicolumn{3}{|c|}{ Pseudo-first order ${ }^{\mathrm{a}}$} & \multicolumn{3}{|c|}{ Maximum oxygen } \\
\hline & & & & & $\begin{array}{c}\text { Range } \\
\text { ( } \mu \mathrm{g} / \mathrm{L})\end{array}$ & $r^{2}$ & $\begin{array}{l}\text { Rate } \\
\left(d^{-1}\right)\end{array}$ & $\begin{array}{c}\text { Available }^{\mathrm{b}} \\
\text { (nmoles) }\end{array}$ & $\begin{array}{c}\text { Consumed } \\
\% \\
\end{array}$ & $\begin{array}{c}\text { Required }^{\mathrm{c}} \\
\% \\
\end{array}$ \\
\hline \multirow{6}{*}{$\begin{array}{l}\text { Ground- } \\
\text { water }\end{array}$} & \multirow{2}{*}{$\begin{array}{c}\text { NSB King } \\
\text { GW1 }\end{array}$} & \multirow[t]{2}{*}{$6-6200$} & Hypoxic & "First" & $6-6200$ & 0.98 & 0.0306 & 600 & 80 & 25 \\
\hline & & & Anoxic & "Saturation" & $6-3100$ & 0.98 & 0.0043 & 120 & $-^{\mathrm{d}}$ & $166 \mathrm{e}$ \\
\hline & \multirow{2}{*}{$\begin{array}{c}\text { NSB King } \\
\text { GW2 }\end{array}$} & \multirow[t]{2}{*}{$6-6200$} & Hypoxic & "First" & $6-6200$ & 0.79 & 0.0564 & 600 & 83 & 38 \\
\hline & & & Anoxic & "Saturation" & $6-3100$ & 0.93 & 0.0042 & 120 & - & 154 \\
\hline & \multirow{2}{*}{$\begin{array}{l}\text { NAWC } \\
\text { Trenton }\end{array}$} & \multirow[t]{2}{*}{$6-6200$} & Hypoxic & "Saturation" & $6-3100$ & 0.95 & 0.0208 & 600 & 28 & 18 \\
\hline & & & Anoxic & "Saturation" & $6-620$ & 0.86 & 0.0002 & 120 & - & 13 \\
\hline \multirow{6}{*}{$\begin{array}{l}\text { Surface } \\
\text { Water }\end{array}$} & \multirow{2}{*}{$\begin{array}{c}\mathrm{DOE} \\
\mathrm{KCP} \\
\mathrm{BR}\end{array}$} & \multirow[t]{2}{*}{$6-6200$} & Hypoxic & "Saturation" & $6-3100$ & 0.99 & 0.0102 & 600 & 84 & 29 \\
\hline & & & Anoxic & "Saturation" & $6-3100$ & 0.98 & 0.0026 & 120 & - & 90 \\
\hline & \multirow{2}{*}{$\begin{array}{c}\mathrm{DOE} \\
\mathrm{KCP} \\
\mathrm{IC}\end{array}$} & \multirow[t]{2}{*}{$6-6200$} & Hypoxic & "First" & $6-6200$ & 0.97 & 0.0103 & 600 & 82 & 29 \\
\hline & & & Anoxic & "Saturation" & $6-3100$ & 0.97 & 0.0037 & 120 & - & 115 \\
\hline & \multirow{2}{*}{$\begin{array}{c}\text { NAS Pens } \\
\text { Bay }\end{array}$} & \multirow[t]{2}{*}{$6-3100$} & Hypoxic & "Saturation" & $6-310$ & 0.94 & 0.0012 & 600 & 100 & 6 \\
\hline & & & Anoxic & $-{ }^{\mathrm{f}}$ & - & - & - & 120 & - & - \\
\hline
\end{tabular}

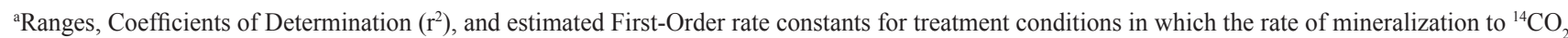
and ${ }^{14} \mathrm{CH}_{4}$ increased linearly with $\mathrm{VC}$ concentration.

${ }^{\text {b}}$ Total $\mathrm{O}_{2}$ initially present in hypoxic treatment microcosms or conservative estimate of the maximum undetected $\mathrm{O}_{2}$ content in anoxic treatments (DO MDL $=0.01 \mathrm{mg} / \mathrm{L}$ ).

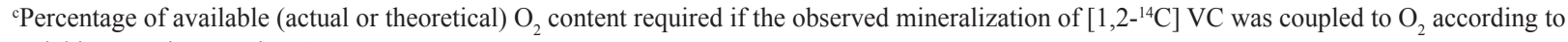
stoichiometry in Equation 1.

${ }^{\mathrm{d} N o t}$ applicable. No detectable $\mathrm{O}_{2}(\mathrm{MDL}=0.01 \mathrm{mg} / \mathrm{L})$ in nominally anoxic treatments.

${ }^{e}$ Values in red indicate a calculated aerobic $\mathrm{O}_{2}$ requirement in excess of the conservative estimate for the maximum $\mathrm{O}_{2}$ available.

${ }^{\mathrm{f}}$ No significant degradation observed in NAS Pensacola Bay sediments under nominally anoxic conditions.

groundwater and surface water sediments from four chloroethene-contaminated sites. An extended range of pseudofirst-order behavior was apparent for the change in DCE/VC mineralization rates with substrate (DCE or VC) concentration (for example, Figure 4). Pseudo-First-Order rate constants for all sediments under hypoxic and nominally anoxic conditions are summarized in Tables 1 and 2 for $\left[1,2-{ }^{14} \mathrm{C}\right] \mathrm{VC}$ and [1,2-

$\left.{ }^{14} \mathrm{C}\right]$ DCE, respectively.

The rate of mineralization of $\left[1,2-{ }^{14} \mathrm{C}\right] \mathrm{VC}$ was significantly higher under hypoxic treatment conditions than under nominally anoxic conditions (Table 1 ), for all treatments. Rates of $\left[1,2-{ }^{14} \mathrm{C}\right] \mathrm{VC}$ mineralization were approximately 1-2 orders of magnitude higher under hypoxic conditions in groundwater sediment treatments and at least 3 times higher under hypoxic treatment conditions for surface water sediments (Table 1). This difference in the extent and rates of mineralization between hypoxic and nominally anoxic treatments provides a quantitative estimate of the relative contribution of $\mathrm{O}_{2}$-linked processes to the biodegradation observed at $\mathrm{DO}$ concentrations of $0.1 \mathrm{mg} / \mathrm{L}$ or less. The results indicate that $\mathrm{O}_{2}$-linked processes on average accounted for at least $85 \%$ and $65 \%$ of the biodegradation of $\left[1,2-{ }^{14} \mathrm{C}\right] \mathrm{VC}$ observed in this study in groundwater and surface-water treatments, respectively (Table 1). The theoretical oxygen demand that may be attributed to $\mathrm{VC}$ mineralization under hypoxic treatment conditions was less than $50 \%$ in all cases (Figure 4; Table 1). Thus, the results demonstrate that $\mathrm{O}_{2}$-linked $\mathrm{VC}$ mineralization can be substantial at DO concentrations between 0.01 and $0.1 \mathrm{mg} / \mathrm{L}$, because hypoxic and anoxic treatments differed only with respect to DO. These results are consistent with the results obtained by Gossett (2010) using an internal, diffusive source of $\mathrm{O}_{2}$. The broad range of pseudo-first behavior observed in this study indicates that hypoxic VC mineralization can be significant at $\mathrm{VC}$ concentrations in excess of $300 \mu \mathrm{g} / \mathrm{L}$.

Significant (recovery of ${ }^{14} \mathrm{C}$-products greater than $4 \%$, or two times the radiochemical purity level) mineralization of $\left[1,2-{ }^{14} \mathrm{C}\right] \mathrm{DCE}$ was also observed in all sediment treatments, with the exception of the sediment from NAS Penasacola Bay (Table 2). However, the rate and extent of $\left[1,2-{ }^{14} \mathrm{C}\right]$ DCE mineralization observed in hypoxic treatments was comparable to that observed under nominally anoxic $(\mathrm{DO}<$ $0.01 \mathrm{mg} / \mathrm{L}$ ) treatment conditions, except in the NAWC Trenton fractured rock treatments. No significant DCE mineralization was observed in nominally anoxic NAWC Trenton treatments, while the highest $\left[1,2-{ }^{14} \mathrm{C}\right]$ DCE mineralization rate observed in this study was for NAWC Trenton core material under hypoxic treatment conditions. The theoretical oxygen demand that could be attributed to the DCE mineralization observed under hypoxic treatment conditions was less than $20 \%$ in all 
Table 2. cis-DCE mineralization kinetics under hypoxic (DO Initial $=90-100 \mu \mathrm{g}-1$ ) and anoxic (MDL $=10 \mu \mathrm{g}$ L-1) conditions. See Figure 5 for a final distribution of ${ }^{14} \mathrm{C}$-products in treatments amended with ${ }^{14} \mathrm{C}$-substrate at an initial concentration of $10 \mu \mathrm{M}$.

\begin{tabular}{|c|c|c|c|c|c|c|c|c|c|c|}
\hline \multirow{2}{*}{ Setting } & \multirow{2}{*}{ Site } & \multirow{2}{*}{$\begin{array}{c}\text { cis-DCE } \\
\text { range } \\
\text { ( } \mu \mathrm{g} / \mathrm{L})\end{array}$} & \multirow{2}{*}{$\begin{array}{l}\text { Oxic } \\
\text { status }\end{array}$} & \multirow{2}{*}{ Kinetics } & \multicolumn{3}{|c|}{ Pseudo-first order } & \multicolumn{3}{|c|}{ Maximum oxygen } \\
\hline & & & & & $\begin{array}{l}\text { Range } \\
\text { ( } \mu \mathrm{g} / \mathrm{L})\end{array}$ & $r^{2}$ & $\begin{array}{l}\text { Rate } \\
\text { (d-1) }\end{array}$ & $\begin{array}{c}\text { Available }^{\mathrm{b}} \\
\text { (nmoles) }\end{array}$ & $\begin{array}{c}\text { Consumed } \\
\%\end{array}$ & $\begin{array}{c}\text { Required }^{\mathrm{c}} \\
\%\end{array}$ \\
\hline \multirow{6}{*}{$\begin{array}{c}\text { Ground- } \\
\text { water }\end{array}$} & \multirow{2}{*}{$\begin{array}{c}\text { NSB King } \\
\text { GW1 }\end{array}$} & \multirow[t]{2}{*}{ 9-9700 } & Hypoxic & "Saturation" & $9-970$ & 0.95 & 0.0009 & 600 & 100 & 4 \\
\hline & & & Anoxic & "Saturation" & $9-970$ & 0.96 & 0.0004 & 120 & $-{ }^{d}$ & 12 \\
\hline & \multirow{2}{*}{$\begin{array}{c}\text { NSB King } \\
\text { GW2 }\end{array}$} & \multirow[t]{2}{*}{$9-9700$} & Hypoxic & "Saturation" & $9-4850$ & 0.90 & 0.0008 & 600 & 80 & 7 \\
\hline & & & Anoxic & "Saturation" & $9-4850$ & 0.98 & 0.0007 & 120 & - & 20 \\
\hline & \multirow{2}{*}{$\begin{array}{l}\text { NAWC } \\
\text { Trenton }\end{array}$} & \multirow[t]{2}{*}{ 9-9700 } & Hypoxic & "Saturation" & $9-4850$ & 0.97 & 0.0107 & 600 & 34 & 28 \\
\hline & & & Anoxic & - & - & - & - & 120 & - & - \\
\hline \multirow{6}{*}{$\begin{array}{l}\text { Surface } \\
\text { Water }\end{array}$} & \multirow{2}{*}{$\begin{array}{c}\text { DOE } \\
\text { KCP } \\
\text { BR }\end{array}$} & \multirow[t]{2}{*}{ 9-9700 } & Hypoxic & "First" & 9-9700 & 0.97 & 0.0012 & 600 & 89 & 15 \\
\hline & & & Anoxic & "Saturation" & 9-970 & 0.95 & 0.0010 & 120 & - & 30 \\
\hline & \multirow{2}{*}{$\begin{array}{l}\mathrm{DOE} \\
\mathrm{KCP} \\
\mathrm{IC}\end{array}$} & \multirow[t]{2}{*}{ 9-9700 } & Hypoxic & "First" & 9-9700 & 0.99 & 0.0005 & 600 & 75 & 6 \\
\hline & & & Anoxic & "Saturation" & 9-970 & 0.94 & 0.0002 & 120 & - & 6 \\
\hline & \multirow{2}{*}{$\begin{array}{c}\text { NAS Pens } \\
\text { Bay }\end{array}$} & \multirow[t]{2}{*}{$9-4850$} & Hypoxic & $-^{\mathrm{e}}$ & - & - & - & 600 & 100 & - \\
\hline & & & Anoxic & - & - & - & - & 120 & - & - \\
\hline
\end{tabular}

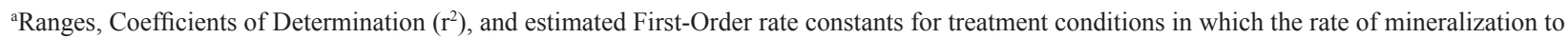
${ }^{14} \mathrm{CO}_{2}$ and ${ }^{14} \mathrm{CH}_{4}$ increased linearly with DCE concentration.

${ }^{b} \mathrm{Total} \mathrm{O}_{2}$ initially present in hypoxic treatment microcosms or conservative estimate of the maximum undetected $\mathrm{O}_{2}$ content in anoxic treatments $(\mathrm{DO} \mathrm{MDL}=0.01 \mathrm{mg} / \mathrm{L})$.

'Percentage of available (actual or theoretical) $\mathrm{O}_{2}$ content required if the maximum observed mineralization of $\left[1,2-{ }^{14} \mathrm{C}\right]$ DCE was coupled to $\mathrm{O}_{2}$ according to stoichiometry in Equation 2.

${ }^{\mathrm{d} N o t}$ applicable. No detectable $\mathrm{O}_{2}(\mathrm{MDL}=0.01 \mathrm{mg} / \mathrm{L})$ in nominally anoxic treatments.

${ }^{\mathrm{e}}$ No significant degradation observed in NAS Pensacola Bay sediments under hypoxic or nominally anoxic conditions.

cases (Table 2). Similar to the pattern observed in $\left[1,2-{ }^{14} \mathrm{C}\right] \mathrm{VC}$ treatments, the extended range of pseudo-first order behavior observed in this study indicates that hypoxic DCE mineralization may be significant at concentrations in excess of $970 \mu \mathrm{g} / \mathrm{L}$. While the NAWC Trenton results demonstrate that $\mathrm{O}_{2}$-linked DCE mineralization can be substantial at DO concentrations between 0.01 and $0.1 \mathrm{mg} / \mathrm{L}$, the general similarity in the extents and rates of mineralization between hypoxic and nominally anoxic treatments suggests that this potential may not be common.

\section{Contribution of Mineralization under Hypoxic Conditions}

${ }^{14} \mathrm{CO}_{2}$ was the primary degradation product observed under hypoxic treatment conditions for both DCE and VC (Figure 5). Products associated with reductive dechlorination (chlororespiration) were observed only in two $\left[1,2-{ }^{14} \mathrm{C}\right]$ DCE treatments and accumulation $\left({ }^{14} \mathrm{C}\right.$-ethene only) was less than $3 \%$ of theoretical in both cases. ${ }^{14} \mathrm{CO}_{2}$ was the only degradation product observed in $\left[1,2-{ }^{14} \mathrm{C}\right] \mathrm{VC}$ treatments under hypoxic conditions (Figure 5).

These results suggest that the failure to recognize the substantial potential for aerobic mineralization at DO concentrations below the field standard for nominally anoxic conditions may lead to significant underestimation of the extent of in situ chloroethene degradation. Due to the current emphasis on accumulation of reductive dechlorination products as an indication of the extent of chloroethene degradation under nominally anoxic conditions, the associated lack of accumulation of diagnostic reductive dechlorination products may lead to the erroneous conclusion that in situ degradation has stalled. In fact, the lack of significant $\left[1,2-{ }^{14} \mathrm{C}\right]$ DCE chlororespiration combined with the 1-2 orders of magnitude higher rates of mineralization of $\left[1,2-{ }^{14} \mathrm{C}\right] \mathrm{VC}$ than $\left[1,2-{ }^{14} \mathrm{C}\right] \mathrm{DCE}$ observed in this study would contribute to the characteristic accumulation of DCE without evidence of further reductive dechlorination; a circumstance that is commonly misdiagnosed as evidence of a so-called DCE stall. 

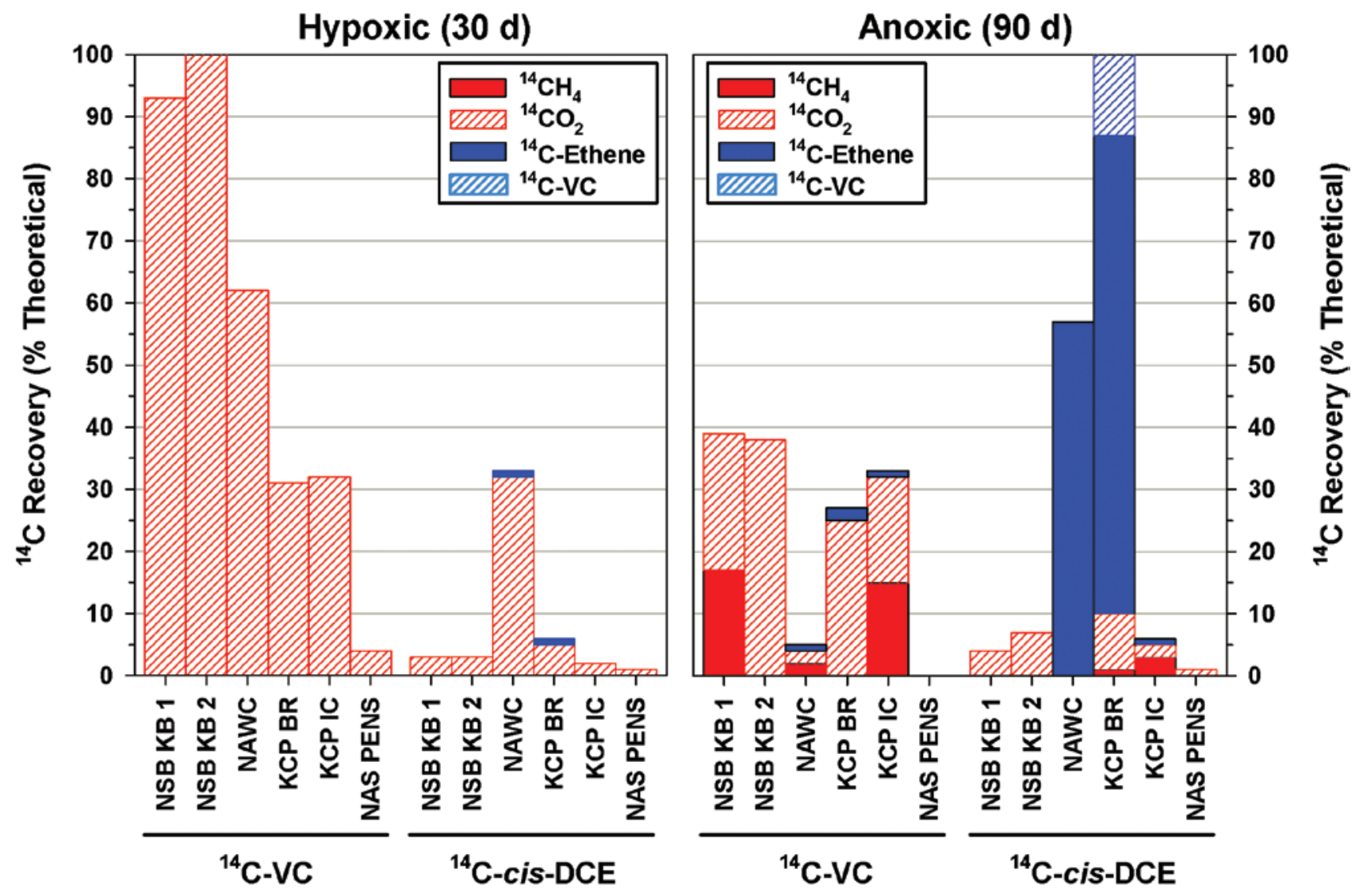

Figure 5. Mean percentage (\% of theoretical) recovery of ${ }^{14} \mathrm{C}$-products in microcosm treatments amended with $\left[1,2-{ }^{14} \mathrm{C}\right]$ VC or $\left[1,2-{ }^{14} \mathrm{C}\right]$ cis-DCE at an initial substrate concentration of $10 \mu \mathrm{M}$. Recoveries observed in hypoxic (30-45 day incubations) and nominally anoxic (85-110 day incubations) treatments were adjusted to 30 and 90 days, respectively, assuming a linear rate of accumulation.

\section{Contribution of Mineralization under Nominally Anoxic Conditions}

Mineralization processes also appeared to dominate the biodegradation of $\left[1,2-{ }^{14} \mathrm{C}\right] \mathrm{VC}$ observed in this study under nominally anoxic conditions (DO less than $\mathrm{O}_{2} \mathrm{MDL}$ of $0.01 \mathrm{mg} / \mathrm{L}$ )(Figure 5). No significant accumulation of ${ }^{14} \mathrm{C}$-degradation products was observed in the strongly $\mathrm{SO}_{4}-$ reducing NAS Pensacola Bay sediments. In all other $\left[1,2-{ }^{14} \mathrm{C}\right]$ $\mathrm{VC}$ amended treatments, which were characterized by active methanogenesis (DOE KCP and NAWC Trenton treatments) or FeIII-reduction (NSB Kings Bay treatments), mineralization products $\left({ }^{14} \mathrm{CO}_{2}\right.$ and $\left.{ }^{14} \mathrm{CH}_{4}\right)$ predominated, comprising $60-100 \%$ of the ${ }^{14} \mathrm{C}$-degradation product accumulation observed under nominally anoxic conditions. These results are consistent with earlier findings of substantial mineralization of $\mathrm{VC}$ in the absence of detectable $\mathrm{O}_{2}$ (for review, see Bradley 2000, 2003) and support earlier concerns that assessing the extent and efficiency of in situ VC biodegradation based solely on accumulation of reductive dechlorination daughter products is problematic (Bradley and Chapelle 2007).

In light of the compelling evidence presented in this study and in the Gossett study (2010) that $\mathrm{O}_{2}$-linked processes can contribute disproportionately to $\mathrm{VC}$ degradation at exceptionally low DO concentrations, a role for $\mathrm{O}_{2}$ in the VC mineralization observed in this study under nominally anoxic treatment conditions cannot be ruled out. However, stoichiometric considerations indicate that processes other than aerobic biodegradation also may be involved. In light of the uncertainties associated with detection limit $\mathrm{O}_{2}$ measurements, a maximum theoretical $\mathrm{O}_{2}$ content of 120 nmoles was assumed for nominally anoxic treatment microcosms. Attributing the mineralization of $\mathrm{VC}$ observed in nominally anoxic DOE KCP treatments to aerobic processes would require the entire theoretical $\mathrm{O}_{2}$ content, despite the substantial organic content (estimated to be $2-4 \%$ of dry weight) and presumptive availability of alternative carbon substrates. The $\mathrm{O}$, required to achieve the VC mineralization observed in NSB Kings Bay anoxic treatments according to the stoichiometry presented in Equation 1 substantially exceeds their theoretical $\mathrm{O}_{2}$ contents. This apparent imbalance between aerobic $\mathrm{O}_{2}$ requirement and $\mathrm{O}_{2}$ availability in nominally anoxic treatments is the basis of previous suggestions that VC mineralization observed in the absence of detectable $\mathrm{O}_{2}(\mathrm{DO} \mathrm{MDL}=0.01 \mathrm{mg} / \mathrm{L})$ may not be linked entirely to free $\mathrm{O}_{2}$ (Bradley et al. 2007a). An interesting hypothetical role for trace $\mathrm{O}_{2}$ might involve an initial $\mathrm{O}_{2}$-linked attack on $\mathrm{VC}$ resulting in reactive intermediates 
susceptible to further degradation by anaerobic respiration or fermentation processes.

Mineralization of $\left[1,2-{ }^{14} \mathrm{C}\right]$ cis-DCE was limited (total accumulation of mineralization products was less than $10 \%$ of theoretical over incubation periods ranging from 85-110 d) in this study under nominally anoxic treatment conditions (Table 2; Figure 5). The only treatments demonstrating greater than $10 \%$ degradation of $\left[1,2-{ }^{14} \mathrm{C}\right]$ cis-DCE were the methanogenic NAWC Trenton and DOE KCP BR sediments (Figure 5). Degradation in these treatments ranged from predominantly (DOE KCP BR) to exclusively (NAWC Trenton) reductive dechlorination.

\section{Role for Low $\mathrm{O}_{2}$ in a Nominally Anoxic Shallow Chloroethene Plume-NSB Kings Bay}

The potential impacts that a precipitation-driven flux of DO into nominally anoxic chloroethene plumes may have on contaminant attenuation are particularly relevant for the many sites where chloroethene contamination occurs in shallow surficial aquifer systems. A recent study of DOC and DO supply to shallow groundwater indicates that shallow DO profiles can be explained by mixing of oxygenated recharge with shallow groundwater (Foulquier et al. 2010). If true, then low DO concentrations in shallow aquifers may, in fact, reflect extensive precipitation-driven advection of DO within the body of the plume rather than indicate the gradient driving diffusive supply of $\mathrm{O}_{2}$ across the oxic/anoxic interface at the plume fringe (Foulquier et al. 2010). Low DO concentrations have been documented widely for shallow, anaerobically active groundwater plumes and generally dismissed as a sampling artifact attributable to atmospheric contamination or the metabolically insignificant DO residual of aerobic consumption at the oxic/ anoxic interface.

The potential importance of $\mathrm{O}_{2}$ in a shallow, anaerobically active chloroethene plume was assessed at NSB Kings Bay. For the period from 2002 through 2007, dissolved VC concentrations in USGS 4 ranged from 1.1-3.0 $\mu \mathrm{M}(68-186$ $\mu \mathrm{g} / \mathrm{L}$ ), with a mean \pm standard deviation (SD) of $2.2 \pm 0.6 \mu \mathrm{M}$ $(136 \pm 37 \mu \mathrm{g} / \mathrm{L} ; \mathrm{n}=18)$ (Figure 3). During the same period, $\mathrm{VC}$ concentrations remained at or below $0.3 \mu \mathrm{M}(<18$ $\mu \mathrm{g} / \mathrm{L})$ with a mean $\pm \mathrm{SD}$ of $0.1 \pm 0.1 \mu \mathrm{M}(6.2 \pm 5.8 \mu \mathrm{g} / \mathrm{L} ; \mathrm{n}=18)$ approximately $40 \mathrm{~m}$ down gradient at USGS 8 , a travel time of approximately 2 years. This statistically significant (MannWhitney Rank Sum; $\mathrm{p}<0.001$ ) decrease indicates a consistent attenuation of more than $70 \%$ without detectable accumulation of ethene or ethane (minimum detection limit $=0.3 \mu \mathrm{M}$ ). Based on a consistent pattern of DO concentrations of 0.1 $\mathrm{mg} / \mathrm{L}$ or less and increasing $\mathrm{Fe}(\mathrm{II})$ concentrations between the USGS 4 transect and the down gradient USGS 8 transect, the redox conditions within this portion of the chloroethene plume have been diagnosed as predominantly $\mathrm{Fe}(\mathrm{III})$-reducing (Chapelle and Bradley 1998; Chapelle et al. 2005; Chapelle and Bradley 2007). The lack of stoichiometric accumulation of ethene and ethane (concentrations at or below detection limit of $0.3 \mu \mathrm{M}$ ) along this groundwater flow path is consistent with previous field (Chapelle and Bradley 1998; Bradley et al. 1998c; Bradley et al. 1998b; Chapelle et al. 2005) and laboratory (Bradley et al. 2005; Bradley et al. 1998b, 1998c, 2005; Bradley and Chapelle 1996, 1997, 1998b, 2007) observations of $\mathrm{VC}$ mineralization to $\mathrm{CO}_{2}$ under predominantly metalsreducing conditions.

Several lines of evidence suggest a possible role for aerobic microbial activity within this nominally anoxic groundwater plume. First, the chloroethene plume at NSB Kings Bay lies within the surficial aquifer, which is overlain by fine grained, permeable sands and subject to significant vertical infiltration of $\mathrm{O}_{2}$ saturated precipitation (Chapelle and Bradley 2007). The frequent observation of detection level (DO concentrations between 0.05 and $0.1 \mathrm{mg} / \mathrm{L}$ ) DO concentrations suggests a flux of DO into the plume (Figure 3)(Chapelle and Bradley 2007), although the ongoing Fe(III)-reduction within the chloroethene plume between the USGS 4 and USGS 8 transects demonstrates that the supply of $\mathrm{O}_{2}$ is not sufficient to prevent the onset and apparent predominance of anaerobic redox conditions (Chapelle and Bradley 1998, 2007; Chapelle et al. 2005). The comparable number of field observations in which DO was not detected (Figure 3) suggests that the trace DO detections at USGS 4 and USGS 8 are not due to intrinsic methodological artifacts caused by atmospheric $\mathrm{O}_{2}$ contamination. The detection of $\mathrm{CO}$, an indicator of $\mathrm{O}_{2}$ infiltration, within the contaminant plume points to a precipitation-driven $\mathrm{O}_{2}$ supply into the predominantly anaerobic plume (Chapelle and Bradley 2007).

\section{Implications for Natural Attenuation in Shallow Chloroethene Plumes}

These results demonstrate the need to reexamine the potential environmental relevance of aerobic metabolism in nominally anoxic chloroethene plumes in shallow surficial aquifer systems and at the groundwater/surface-water interface. The historical presumption that aerobic processes are unimportant in anaerobically-active chloroethene plumes requires several poorly supported simplifying assumptions: (1) that DO noncompetitively and completely inhibits anaerobic activity such that evidence of significant anaerobic activity precludes the occurrence of DO even at low concentrations, (2) that little spatial or temporal variation in the concentration and distribution of DO occurs in "stable" groundwater plumes, and (3) that DO concentrations greater than the $0.1-0.5 \mathrm{mg} / \mathrm{L}$ field standard for nominally anoxic conditions are required to achieve aerobic chloroethene biodegradation at a scale relevant to overall site remediation.

The first assumption is not supported by the literature. Historically, the term "strict anaerobe" referred to microorganisms that were able to couple growth and metabolism to other substrates than $\mathrm{O}_{2}$ and were incapable of growth at atmospheric oxygen levels (Morris 1976). Enzymatic defenses against oxygen radicals have been documented 
in microorganisms typically identified as strict anaerobes, indicating that the ability to survive and in some cases grow at low DO concentrations is common in anaerobic communities (Krieg and Hoffman 1986; Kato et al. 1993; Marschall et al. 1993). Thus, while irreversible metabolic damage from $\mathrm{O}_{2}$ exposure is viewed as a fundamental control on anaerobic biodegradation activity, including VC chlororespiration (Adrian et al. 2007; Amos et al. 2008); many anaerobes including PCE/TCE chlororespirers (He et al. 2003; Adrian et al. 2007; Amos et al. 2008) are tolerant of $\mathrm{O}_{2}$ exposure. In particular, $\mathrm{NO}_{3}$-reducing (Hernandez and Rowe 1987; Hordijk et al. 1987) and FeIII-reducing (Arnold et al. 1986; Arnold et al. 1990; Lin et al. 2004; Ruebush et al. 2006; Tang et al. 2007) activity can be substantial in the presence of $\mathrm{O}_{2}$, particularly at low DO concentrations. For example, the documentation that the FeIII-reducer, Geobacteriacae sulfurreducens, can maintain FeIII-reduction at low $\mathrm{O}_{2}$ concentrations and even grow on $\mathrm{O}_{2}$, suggests that FeIII-reducers perhaps should be viewed as facultative anaerobes (Lin et al. 2004) and emphasizes the point that active FeIII-reduction and low DO concentrations are not mutually exclusive.

The last two assumptions are equally problematic. Redox conditions can vary considerably, both spatially and temporally, in shallow surficial groundwater systems (Vroblesky and Chapelle 1994). The fact that genes coding for metabolic defenses against oxygen radicals (Fridovich 1998) are highly conserved in obligate anaerobes indicates that periodic $\mathrm{O}_{2}$ exposure is an important component of this redox variability in anaerobically active shallow groundwater environments (Rolfe et al. 1978; Krieg and Hoffman 1986; Kato et al. 1993; Marschall et al. 1993; Fridovich 1998). Likewise, mineralization of DCE and VC at DO concentrations below the current field standard for nominally anoxic conditions $(0.1-0.5 \mathrm{mg} / \mathrm{L})$ can be substantial (Bradley and Chapelle 1996, 1997, 1998b, 1999a, 1999b, 2000a; Bradley et al. 1998a,1998b, 1998c; Singh et al. 2004; Gossett 2010) in groundwater and surfacewater systems.

Chlororespiration is common in shallow aquifer systems under conditions nominally identified as anoxic and, consequently, is a fundamental component of remediation at most chloroethene-contaminated sites. However, emphasizing chlororespiration under nominally anoxic conditions $(\mathrm{DO}<$ $0.1-0.5 \mathrm{mg} / \mathrm{L}$ ) to the extent that in situ accumulation of DCE without concomitant accumulation of reduced, chlorinated daughter products like VC or non-chlorinated daughter products like ethene (and by extension ethane) is considered prima facie evidence of incomplete degradation, a so-called degradative stall, rather than acknowledging the significant potential for mineralization that exists in these environments is unjustified. In this study, $\mathrm{O}_{2}$-linked processes on average accounted for at least $85 \%$ and $65 \%$ of the biodegradation of $\left[1,2-{ }^{14} \mathrm{C}\right]$ $\mathrm{VC}$ observed in groundwater and surface-water treatments, respectively, at DO concentrations below $0.1 \mathrm{mg} / \mathrm{L}$. Clearly, improved methods for assessment of the role and potential importance of oxygen in chloroethene biodegradation are needed, because mischaracterization of operant biodegradation processes can lead to expensive and ineffective remedial actions. A modified redox assessment framework, which addresses the potential contribution of aerobic mineralization processes to in situ chloroethene attenuation, is presented by Bradley (2011).

\section{Acknowledgments}

This research was funded by the U.S. Geological Survey Toxics Substances Hydrology Program and the Strategic Environmental Restoration and Defense Program of the DOE, DOD and USEPA. Any use of trade, product, or firm names is for descriptive purposes only and does not imply endorsement by the U.S. Government.

Reprinted from Ground Water Monitoring \& Remediation with permission of the National Ground Water Association.

The definitive version of this article is available at www.Blackwell-Synergy.com

\section{References}

Adrian, L., S.K. Hansen, J.M. Fung, H. Gorisch, and S.H. Zinder. 2007. Growth of Dehalococcoides strains with chlorophenols as electron acceptors. Environmental Science \& Technology 41, no. 7: 2318-2323.

Amos, B.K., K.M. Ritalahti, C. Cruz-Garcia, E. Padilla-Crespo, and F.E. Loffler. 2008. Oxygen effect on Dehalococcoides viability and biomarker quantification. Environmental Science \& Technology 42, no. 15: 5718-5726.

Arnold, R.G., M.R. Hoffmann, T.J. DIChristina, and F.W. Picardal. 1990. Regulation of dissimilatory Fe(III) reduction activity in Shewanella putrefaciens. Applied and Environmental Microbiology 56, no. 9: 2811-2817.

Arnold, R.G., T.J. DiChristina, and M.R. Hoffmann. 1986. Inhibitor studies of dissimilative $\mathrm{Fe}(\mathrm{III})$ reduction by Pseudomonas sp. strain 200 ("Pseudomonas ferrireductans"). Applied and Environmental Microbiology 52, no. 2: 281-289.

Bradley, P. 2003. History and ecology of chloroethene biodegradation: a review. Bioremediation Journal 7 no. 2: 81-109.

Bradley, P. 2000. Microbial degradation of chloroethenes in groundwater systems. Hydrogeology Journal 8 no. 1: 104-111.

Bradley, P. 2011. Reinterpreting the importance of oxygenbased biodegradation in chloroethene-contaminated groundwater. Groundwater Monitoring \& Remediation. In Press. 
Bradley, P., P. Lacombe, T. Imbrigiotta, F. Chapelle, and D. Goode. 2009. Flowpath independent monitoring of reductive dechlorination potential in a fractured rock aquifer. Ground Water Monitoring \& Remediation 29, no. 4: 46-55.

Bradley, P., and F. Chapelle. 2007. Accumulation of dechlorination daughter products: A valid metric of chloroethene biodegradation? Remediation Journal 17, no. 4: 7-22.

Bradley, P., F. Chapelle, and F. Löffler. 2007a. Anoxic mineralization: Environmental reality or experimental artifact? Ground Water Monitoring and Remediation 28, no. 1: 47-49.

Bradley, P., M. Singletary, and F. Chapelle. 2007b. Chloroethene dechlorination in acidic groundwater: Implications for combining fenton's treatment with natural attenuation. Remediation Journal 18, no. 1:7-19.

Bradley, P., S. Richmond, and F. Chapelle. 2005. Chloroethene biodegradation in sediments at $4^{\circ} \mathrm{C}$. Applied and Environmental Microbiology 71, no. 10: 6414.

Bradley, P., and F. Chapelle. 2002. Microbial mineralization of ethene under sulfate-reducing conditions. Bioremediation Journal 6, no. 1: 1-8.

Bradley, P., J. Landmeyer, and F. Chapelle. 2002a. TBA biodegradation in surface-water sediments under aerobic and anaerobic conditions. Environmental Science \& Technology 36, no. 19: 4087-4090.

Bradley, P.M., J.E. Landmeyer, and F.H. Chapelle. 2002b. TBA biodegradation in surface-water sediments under aerobic and anaerobic conditions. Environmental Science \& Technology 36, no. 19: 4087-4090.

Bradley, P., F. Chapelle, and J. Landmeyer. 2001a. Effect of redox conditions on MTBE biodegradation in surface water sediments. Environmental Science \& Technology 35, no. 23: 4643-4647.

Bradley, P., J. Landmeyer, and F. Chapelle. 2001b. Widespread potential for microbial MTBE degradation in surface-water sediments. Environmental Science \& Technology 35, no. 4: 658-662.

Bradley, P., and F. Chapelle. 2000a. Acetogenic microbial degradation of vinyl chloride. Environmental Science \& Technology 34, no. 13: 2761-2763.

Bradley, P., and F. Chapelle. 2000b. Aerobic microbial mineralization of dichloroethene as sole carbon substrate. Environmental Science \& Technology 34, no. 1: 221-223.

Bradley, P., and F. Chapelle. 1999a. Methane as a product of chloroethene biodegradation under methanogenic conditions. Environmental Science \& Technology 33, no. 4: 653-656.
Bradley, P., and F. Chapelle. 1999b. Role for acetotrophic methanogens in methanogenic biodegradation of vinyl chloride. Environmental Science \& Technology 33, no. 19: 3473-3476.

Bradley, P., and F. Chapelle. 1998a. Effect of contaminant concentration on aerobic microbial mineralization of DCE and VC in stream-bed sediments. Environmental Science \& Technology 32, no. 5: 553-557.

Bradley, P., and F. Chapelle. 1998b. Microbial mineralization of $\mathrm{VC}$ and DCE under different terminal electron accepting conditions Anaerobe 4, no. 2: 81-87.

Bradley, P., F. Chapelle, and D. Lovley. 1998a. Humic acids as electron acceptors for anaerobic microbial oxidation of vinyl chloride and dichloroethene. Applied and Environmental Microbiology 64, no. 8: 3102.

Bradley, P., F. Chapelle, and J. Wilson. 1998b. Field and laboratory evidence for intrinsic biodegradation of vinyl chloride contamination in a Fe (III)-reducing aquifer. Journal of Contaminant Hydrology 31, no. 1-2: 111-127.

Bradley, P., J. Landmeyer, and R. Dinicola. 1998c. Anaerobic oxidation of $\left[1,2-{ }^{14} \mathrm{C}\right]$ dichloroethene under Mn (IV)-reducing conditions. Applied and Environmental Microbiology 64, no. 4: 1560-1562.

Bradley, P., and F. Chapelle. 1997. Kinetics of DCE and VC mineralization under methanogenic and Fe (III)-reducing conditions. Environmental Science \& Technology 31, no. 9: 2692-2696.

Bradley, P., and F. Chapelle. 1996. Anaerobic mineralization of vinyl chloride in $\mathrm{Fe}$ (III)-reducing, aquifer sediments. Environmental Science \& Technology 30, no. 6: 2084-2086.

Chapelle, F., and P. Bradley. 2007. Hydrologic significance of carbon monoxide concentrations in ground water. Ground Water 45, no. 3: 9 .

Chapelle, F., P. Bradley, and C. Casey. 2005. Behavior of a chlorinated ethene plume following source-area treatment with Fenton's reagent. Ground Water Monitoring \& Remediation 25, no. 2: 131-141.

Chapelle, F., and P. Bradley. 1998. Selecting remediation goals by assessing the natural attenuation capacity of groundwater systems. Bioremediation Journal 2, no. 3: 227-238.

Coleman, N.V., T.E. Mattes, J.M. Gossett, and J.C. Spain. 2002a. Biodegradation of cis-dichloroethene as the sole carbon source by a beta-proteobacterium. Applied and Environmental Microbiology 68, no. 6: 2726-2730. 
Coleman, N.V., T.E. Mattes, J.M. Gossett, and J.C. Spain. 2002b. Phylogenetic and kinetic diversity of aerobic vinyl chloride-assimilating bacteria from contaminated sites.

Applied and Environmental Microbiology 68, no. 12: 6162-6171.

Foulquier, A., F. Malard, F. Mermillod-Blondin, T. Datry, L. Simon, B. Montuelle, and J. Gibert. 2010. Vertical change in dissolved organic carbon and oxygen at the water table region of an aquifer recharged with stormwater: Biological uptake or mixing? Biogeochemistry 99, no. 1: 31-47.

Fridovich, I. 1998. Oxygen toxicity: A radical explanation. Journal of Experimental Biology 201, no. 8: 1203-1209.

Gossett, J.M. 2010. Sustained aerobic oxidation of vinyl chloride at low oxygen concentrations. Environmental Science \& Technology 44, no. 4: 1405-1411.

He, J., K.M. Ritalahti, M.R. Aiello, and F.E. Loffler. 2003. Complete detoxification of vinyl chloride by an anaerobic enrichment culture and identification of the reductively dechlorinating population as a Dehalococcoides species. Applied and Environmental Microbiology 69, no. 2: 996-1003.

Hernandez, D., and J.J. Rowe. 1987. Oxygen regulation of nitrate uptake in denitrifying Pseudomonas aeruginosa. Applied and Environmental Microbiology 53, no. 4: 745-750.

Hordijk, C.A., M. Snieder, J.J.M. Van Engelen, and T.E. Cappenberg. 1987. Estimation of bacterial nitrate reduction rates at in situ concentrations in freshwater sediments. Applied and Environmental Microbiology 53, no. 2: 217-223.

Kato, M.T., J.A. Field, and G. Lettinga. 1993. High tolerance of methanogens in granular sludge to oxygen. Biotechnology and Bioengineering 42, no. 11: 1360-1366.

Krieg, N.R., and P.S. Hoffman. 1986. Microaerophily and oxygen toxicity. Annual Review of Microbiology 40, no. 1: 107-130.

Lin, W.C., M.V. Coppi, and D.R. Lovley. 2004. Geobacter sulfurreducens can grow with oxygen as a terminal electron acceptor. Applied and Environmental Microbiology 70, no. 4: 2525-2528.

Lovley, D.R., and E.J. Phillips. 1986. Organic matter mineralization with reduction of ferric iron in anaerobic sediments. Applied and Environmental Microbiology 51, no. 4: 683-689.
Marschall, C., P. Frenzel, and H. Cypionka. 1993. Influence of oxygen on sulfate reduction and growth of sulfate-reducing bacteria. Archives of Microbiology 159, no. 2: 168-173.

Morris, J. 1976. Fifth Stenhouse-Williams memorial lecture oxygen and the obligate anaerobe. Journal of Applied Microbiology 40, no. 3: 229-244.

Rolfe, R., D. Hentges, B. Campbell, and J. Barrett. 1978. Factors related to the oxygen tolerance of anaerobic bacteria. Applied and Environmental Microbiology 36, no. 2: 306.

Ruebush, S.S., S.L. Brantley, and M. Tien. 2006. Reduction of soluble and insoluble iron forms by membrane fractions of Shewanella oneidensis grown under aerobic and anaerobic conditions. Applied and Environmental Microbiology 72, no. 4: 2925-2935.

Singh, H., F. Löffler, and B. Fathepure. 2004. Aerobic biodegradation of vinyl chloride by a highly enriched mixed culture. Biodegradation 15, no. 3: 197-204.

Tang, Y.J., J.S. Hwang, D.E. Wemmer, and J.D. Keasling. 2007. Shewanella oneidensis MR-1 fluxome under various oxygen conditions. Applied and Environmental Microbiology 73 , no. 3: 718-729.

Vogel, T.M., C.S. Criddle, and P.L. McCarty. 1987. ES critical reviews: Transformations of halogenated aliphatic compounds. Environmental Science \& Technology 21, no. 8: 722-736.

Vroblesky, D., and F. Chapelle. 1994. Temporal and spatial changes of terminal electron-accepting processes in a petroleum hydrocarbon-contaminated aquifer and the significance for contaminant biodegradation. Water Resources Research 30, no. 5: 1561-1570.

\section{Biographical Sketches}

Paul M. Bradley, PhD, corresponding author, is a research ecologist at U.S. Geological Survey, South Carolina Water Science Center, Columbia, SC 29210; (803) 750-6125; fax (803)750-6181; bradley@usgs.gov.

Francis H. Chapelle, PhD, is a research hydrologist at U.S. Geological Survey, South Carolina Water Science Center, and Columbia, SC 29210. 


\title{
Chapter 4. Reinterpreting the Importance of Oxygen- Based Biodegradation in Chloroethene-Contaminated Groundwater
}

\author{
By Paul M. Bradley
}

\section{Abstract}

Chlororespiration is common in shallow aquifer systems under conditions nominally identified as anoxic. Consequently, chlororespiration is a key component of remediation at many chloroethene-contaminated sites. In some instances, limited accumulation of reductive dechlorination daughter products is interpreted as evidence that natural attenuation is not adequate for site remediation. This conclusion is justified when evidence for parent compound (tetrachloroethene, PCE, or trichloroethene, TCE) degradation is lacking. For many chloroethene-contaminated shallow aquifer systems, however, nonconservative losses of the parent compounds are clear but the mass balance between parent compound attenuation and accumulation of reductive dechlorination daughter products is incomplete. Incomplete mass balance indicates a failure to account for important contaminant attenuation mechanisms and is consistent with contaminant degradation to nondiagnostic mineralization products like $\mathrm{CO}_{2}$. While anoxic mineralization of chloroethene compounds has been proposed previously, recent results suggest that oxygen-based mineralization of chloroethenes also can be significant at dissolved oxygen concentrations below the currently accepted field standard for nominally anoxic conditions. Thus, reassessment of the role and potential importance of low concentrations of oxygen in chloroethene biodegradation are needed, because mischaracterization of operant biodegradation processes can lead to expensive and ineffective remedial actions. A modified interpretive framework is provided for assessing the potential for chloroethene biodegradation under different redox conditions and the probable role of oxygen in chloroethene biodegradation.

\section{Background}

Microbial mechanisms for degradation of reduced (e.g., petroleum hydrocarbons) and oxidized (e.g., chloroethenes) groundwater contaminants are fundamentally redox processes. Consequently, in situ redox conditions control the efficiency of biodegradation, and natural attenuation assessment protocols for both contaminant types typically include characterization of redox conditions within and downgradient of the contaminant plume (Barcelona 1994; Wiedemeier et al. 1994, 1998, 1999a, 1999b, 1999c; Chapelle et al. 1995; Chapelle 1996; Chapelle et al. 1996, 2002). Recommended procedures for field sampling and analysis of dissolved oxygen and other redox parameters, including specific cautions against methods (e.g., bailers) that disturb/aerate the sample, are discussed in detail elsewhere (Appendix A-4 in Wiedemeier et al. 1998; Kampbell and Chapelle 2002; Wilkin and Ptacek 2002). Frameworks for systematic characterization of redox conditions and for interpreting the impact of redox conditions on contaminant biodegradation were initially developed for petroleum-hydrocarbon-contaminated groundwater systems in the early 1990s (Barcelona 1994; Wiedemeier et al. 1994, 1999a, 1999b; Chapelle et al. 1995; Chapelle et al. 1996). The same fundamental approach was subsequently incorporated into assessment protocols for natural attenuation and engineered biodegradation at chloroethene-contaminated sites (Chapelle 1996; Wiedemeier et al. 1998, 1999a, 1999c; Chapelle et al. 2002).

Although procedures for groundwater redox characterization are directly transferrable, important differences in the redox character of these two contaminant types dictate the use of different interpretive frameworks for assessing the impact of in situ redox conditions on the potential for contaminant biodegradation. In particular, interpreting the importance of oxygen in contaminant biodegradation depends greatly on contaminant redox character. This article discusses the fundamental differences in redox character between petroleum hydrocarbon and chloroethene contaminants along with the impact that these differences have on the relationship between contaminant biodegradation efficiency and in situ dissolved oxygen. A modified interpretive framework is provided for assessing the potential for chloroethene biodegradation under different redox conditions and the probable role of oxygen in chloroethene biodegradation.

\section{Contaminant Redox Character}

\section{Petroleum Hydrocarbons}

Petroleum hydrocarbon compounds generally serve as electron donors during respiratory microbial degradation (Figure 6). Because the energy available for microbial metabolism is a function of the potential difference between the electron donor and the terminal electron acceptor, the theoretical 


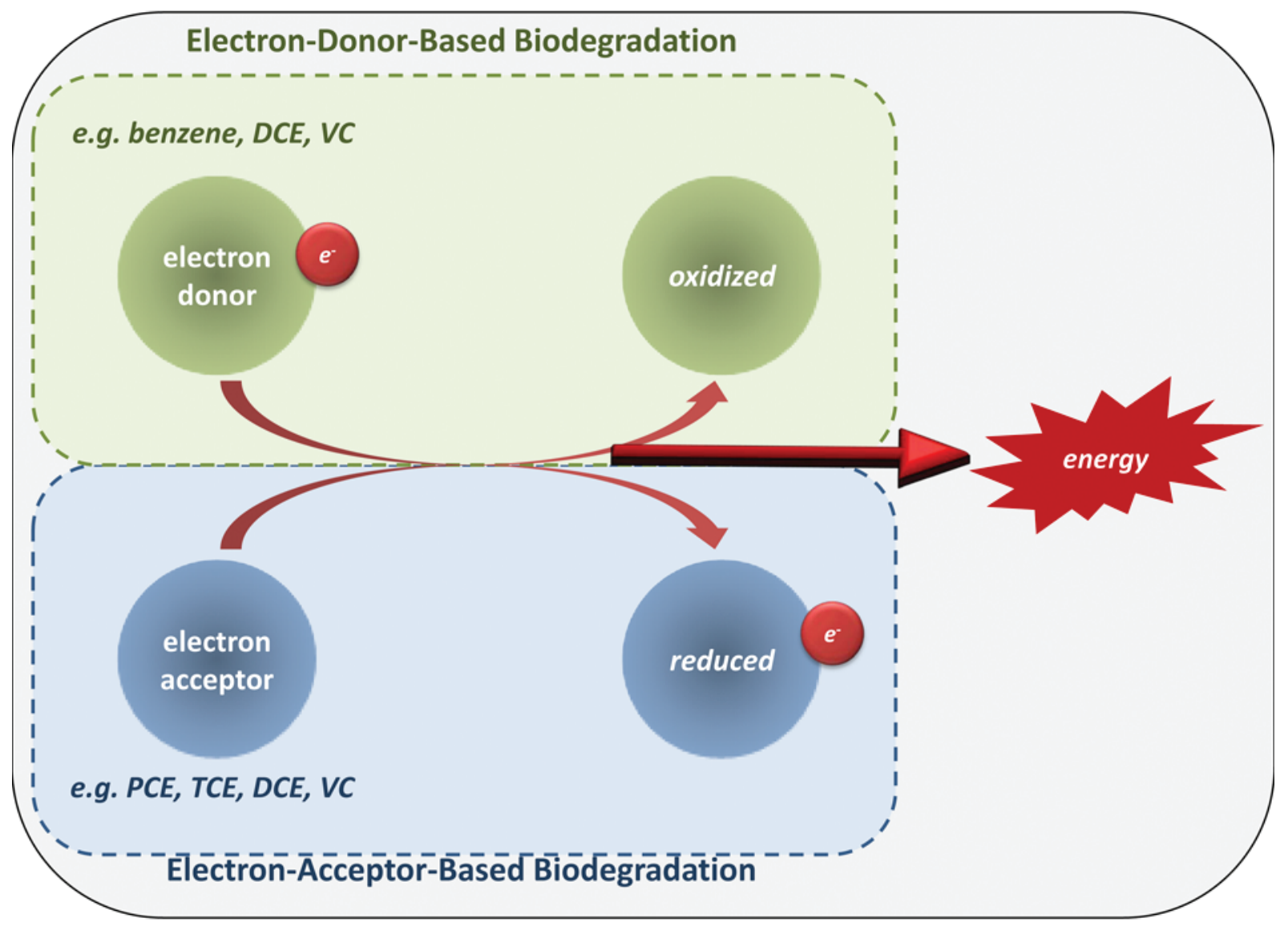

Figure 6. During biodegradation, contaminants can serve as electron donors (e.g. benzene, DCE, VC) or as electron acceptors (e.g. PCE, TCE, DCE, VC) for microbial respiration, a process that yields energy for metabolism and growth.

energy yield from the biodegradation of a given petroleum hydrocarbon compound typically is greatest when coupled to oxygen, and decreases in the order of oxygen-reduction $>$ nitrate-reduction $>\mathrm{Fe}(\mathrm{III})$-reduction $>$ sulfate reduction $>$ methanogenesis.

Microcosm results and field-based biodegradation assessments generally agree with this theoretical prediction (for review see Wiedemeier et al. 1999b). Significant petroleum hydrocarbon biodegradation has been demonstrated under a range of terminal electron accepting conditions. However, rates of petroleum hydrocarbon biodegradation under oxic conditions are typically 1-2 orders of magnitude greater than under anoxic conditions and biodegradation is generally poor under methanogenic conditions. Equally important from an environmental impact point of view, aerobic biodegradation typically involves complete degradation to mineralization products, avoiding the accumulation of noxious fermentation products.

Thus a fundamental question when assessing the impact of redox conditions on the potential for petroleum hydrocarbon biodegradation is, "What is the dissolved oxygen concentration 'threshold' below which the contribution of oxygen-based microbial metabolism to contaminant remediation becomes insignificant?"

\section{Chloroethenes}

The fact that chloroethenes can serve as either electron acceptors or electron donors during biodegradation (Figure 6) complicates the relationship between redox condition and efficiency of chloroethene biodegradation (Bradley 2003). Polychlorinated parent compounds like PCE and TCE are highly oxidized and efficient biodegradation is achieved primarily when serving as electron acceptors. Chlororespiring microorganisms are specifically adapted to using chlorinated compounds as electron acceptors.

Diatomic oxygen may inhibit chlororespiration via noncompetitive and competitive mechanisms. Diatomic oxygen appears to be toxic to chlororespiratory microorganisms (He et al. 2003; Adrian et al., 2007), inactivating essential chlororespiratory enzymes (Amos et al., 2008). PCE and TCE chlororespiration activity appears to recover shortly after oxygen removal, but oxygen inhibition of vinyl chloride (VC) 
chlororespiratory enzymes appears to be long-term and, potentially, irreversible (Amos et al., 2008).

Aerobic microorganisms also may inhibit chlororespiration by outcompeting chlororespirers for available electron donor. Oxygen is a stronger oxidant than the chloroethene compounds, including PCE (Vogel et al. 1987, Vogel 1994, Wiedemeier et al. 1999c). All currently identified chloroethene chlororespirers are obligate hydrogenotrophs. Thus, at least two general mechanisms of substrate competition are available to aerobic microorganisms: 1) direct competition for available $\mathrm{H}_{2}$, and 2) indirect electron donor competition. Aerobic hydrogenotrophs are ubiquitous in soil and sediment (Bowien and Schelegel, 1981; Friedrich and Schwartz, 1993), but their activity in these environments is unclear and their affinity for $\mathrm{H}_{2}$ is reportedly poor (Friedrich and Schwartz, 1993). Consequently, the potential for direct $\mathrm{H}_{2}$ competition remains unclear. On the other hand, aerobic microorganisms utilize a variety of complex compounds as electron donors, including the substrates and intermediate products involved in fermentation. Thus, aerobes may sequester the electron donor flow and thereby inhibit fermentative production of the $\mathrm{H}_{2}$ required for chlororespiration.

Efficient chlororespiration of polychlorinated contaminants, therefore, requires that the oxygen concentration of the groundwater system be low enough to 1) avoid "poisoning" the chlororespiratory enzymes and 2) minimize electron donor competition by aerobic microorganisms. Consequently, chlororespiratory degradation is generally favored under anoxic conditions. A fundamental question when assessing the impact of redox conditions on the potential for biodegradation of polychlorinated chloroethenes is, "What is the dissolved oxygen concentration 'threshold' below which chlororespiration becomes significant?"

While dichloroethene (DCE) and VC can serve as terminal electron acceptors for chlororespiration, they can also serve as electron donors. Like petroleum hydrocarbons, degradation of DCE and VC as electron donors is favored in the presence of a strong terminal electron acceptor, with rates of biodegradation substantially higher in the presence of oxygen than under anoxic conditions and generally poor potential for electron donor biodegradation under reducing conditions (Bradley and Chapelle, 1997, 1998a, 1998b).

DCE and VC biodegradation at low concentrations of dissolved oxygen may be a key contaminant attenuation mechanism (Gossett 2010; Bradley and Chapelle 2011), and failure to recognize this process can have important consequences. Existing protocols for assessing in situ biodegradation of chloroethene contaminants focus on chlororespiration. Accordingly, the accumulations of reductive dechlorination products like DCE, VC, ethene, and, by extension, ethane are prima facie evidence of ongoing reductive dechlorination biodegradation. Aerobic microbial processes can degrade all of these compounds to $\mathrm{CO}_{2}$. Consequently, unless the role of oxygen is recognized, the associated lack of reductive dechlorination products will be interpreted incorrectly as evidence of incomplete degradation, a so-called degradative "stall."
As was the case for petroleum hydrocarbon contaminants, a fundamental question when assessing the impact of redox conditions on the potential for biodegradation of DCE and $\mathrm{VC}$ is, "What is the dissolved oxygen concentration 'threshold' below which the contribution of oxygen-based microbial metabolism to contaminant remediation becomes insignificant?"

\section{Interpreting the Contribution of Oxygen to Biodegradation}

The following criteria indicate the potential importance of oxygen in contaminant biodegradation:

- The comparative rate of biodegradation under oxic versus anoxic conditions.

- The extent to which the contaminant molecule is degraded (i.e. mineralization versus transformation) under oxic versus anoxic conditions.

- The relative mass balance of contaminant and oxygen supply (i.e. fraction of contaminant mass that may be degraded by the available oxygen supply).

\section{Electron-Donor-Based Biodegradation of Petroleum Hydrocarbons}

Biodegradation rates for petroleum hydrocarbon compounds, including the soluble carcinogen benzene, decrease systematically with decreasing electron acceptor potential and are typically higher by an order of magnitude or more when coupled to aerobic rather than anaerobic respiration (for review see Wiedemeier et al. 1999b). Aerobic biodegradation of petroleum hydrocarbon contaminants often involves mineralization to $\mathrm{CO}_{2}$, and avoids the accumulation of noxious byproducts frequently observed under anoxic conditions. Thus, the importance of oxygen to petroleum hydrocarbon biodegradation under in situ conditions depends on the third criterion,

$$
\begin{aligned}
\mathrm{C}_{6} \mathrm{H}_{6} & +7.50_{2} \leftrightarrow 6 \mathrm{CO}_{2}+3 \mathrm{H}_{2} \mathrm{O} \\
& \text { - } \\
\text { - } & \text { Molar ratio }=1: 7.5 \\
& \text { Mass ratio }=1: 3
\end{aligned}
$$

the balance between contaminant mass and oxygen supply. For this reason, the presence/absence and the apparent supply of dissolved oxygen are key diagnostic parameters in petroleum hydrocarbon plumes (Wiedemeier et al. 1994, 1999b).

Established protocols for assessing the favorability of redox conditions for petroleum hydrocarbon biodegradation generally conclude that, at dissolved oxygen concentrations below the $0.1-0.5 \mathrm{mg} / \mathrm{L}$ field standard, the contribution of aerobic biodegradation processes to overall contaminant attenuation is limited (Wiedemeier et al. 1994, 1999b). This standard does not imply that aerobic activity is not occurring at these 
dissolved oxygen concentrations. Rather, at concentrations below the standard the supply of oxygen is limited, such that the contribution of aerobic processes to contaminant attenuation plume-wide becomes less important than other processes, including anaerobic degradation. A fundamental factor in the decision to use $0.1-0.5 \mathrm{mg} / \mathrm{L}$ as a field standard for anoxic conditions was the fact that dissolved contaminant concentrations in petroleum hydrocarbon plumes are commonly in the 1-100 mg/L range (Wiedemeier et al. 1999b). Accordingly, stoichiometric considerations dictate a correspondingly large mass of oxygen to remediate the high mass of petroleum hydrocarbons in a typical plume (Wiedemeier et al. 1999b). For example, $3 \mathrm{mg} / \mathrm{L}$ of oxygen is required to mineralize 1 $\mathrm{mg} / \mathrm{L}$ benzene, just one of the many compounds in the petroleum hydrocarbon complex. Without continued resupply, a dissolved oxygen concentration of $0.5 \mathrm{mg} / \mathrm{L}$ would correspond to an insignificant fraction of the total contaminant mass in a typical petroleum hydrocarbon plume. While the concentration of dissolved oxygen reflects the balance between supply and consumption and not the rate of supply, it is typically assumed that the supply of dissolved oxygen is limiting, if the observed concentration of dissolved oxygen is below the field standard and if other redox parameters indicate active anaerobic metabolism. In light of the technical challenges associated with dissolved oxygen determinations in the field and the large margin of error afforded by the high contaminant mass that typifies most petroleum-hydrocarbon plumes, the $0.1-0.5$ $\mathrm{mg} / \mathrm{L}$ field standard continues to be a reasonable compromise.

\section{Electron-Acceptor-Based Biodegradation of Chloroethenes}

Because oxygen can inhibit chlororespiration by competitive and non-competitive mechanisms, polychlorinated chloroethenes, like PCE and TCE, are frequently recalcitrant in oxic groundwater. Thus, to determine the impact of oxygen on this specific degradative process, the relevant question is whether in situ dissolved oxygen is low enough to avoid a concentration-dependent inhibition of chlororespiration activity. In accordance with the established logic, that aerobic metabolism dominates electron flow at dissolved oxygen concentrations above the $0.1-0.5 \mathrm{mg} / \mathrm{L}$ field standard; dissolved oxygen concentrations must fall below this field detection threshold to minimize aerobic electron donor competition. Likewise, while the dissolved oxygen concentration threshold for inactivation ("poisoning") of chlororespiration enzymes has not been clearly established, strict anoxic conditions are required to avoid inactivation of commercial chlororespiration microbial cultures and trace oxygen contamination has been reported to inactivate chlororespiration in laboratory cultures (He et al. 2003; Adrian et al., 2007; Amos et al. 2008). These observations indicate that the dissolved oxygen threshold for non-competitive inhibition also is below the field detection standard.
In the absence of a precisely defined oxygen inhibition threshold, some potential for PCE and TCE chlororespiration may reasonably be assumed if dissolved oxygen concentrations are below the field standard. Obviously, production of the reductive dechlorination products, DCE and VC, is incontrovertible evidence of chlororespiration within the plume. Ongoing anaerobic terminal electron accepting processes (e.g., $\mathrm{Mn} / \mathrm{Fe}$-reduction) and/or highly reducing conditions (e.g., elevated dissolved $\mathrm{H}_{2}$ concentrations) provide independent corroboration that in situ dissolved oxygen concentrations are low enough to allow chlororespiration of PCE and TCE. Because of the demonstrated potential for DCE and VC mineralization in the absence of detectable oxygen (Gossett 2010; Bradley and Chapelle 2011), however, stoichiometric accumulation of DCE and VC cannot be assumed and the absence of DCE and VC does not preclude significant in situ PCE/TCE chlororespiration, unless the "complete absence" of dissolved oxygen is corroborated.

\section{Electron-Donor-Based Biodegradation of DCE and VC}

Rates of electron-donor-based biodegradation of DCE and $\mathrm{VC}$ are typically higher by an order of magnitude or more when coupled to aerobic rather than anaerobic respiration (Bradley and Chapelle 1997, 1998a, 1998b, 2011; Gossett 2010). Moreover, aerobic biodegradation of DCE and VC involves mineralization to non-toxic products, and avoids the accumulation of toxic by-products (e.g., production of carcinogenic VC during DCE chlororespiration) that is frequently observed under anoxic conditions. Thus, like petroleum hydrocarbon contaminants, the potential importance of oxygen to electron-donor-based biodegradation of DCE or VC depends

$$
\begin{aligned}
\mathrm{C}_{2} \mathrm{H}_{6} \mathrm{Cl} & +2.50_{2} \leftrightarrow 2 \mathrm{CO}_{2}+\mathrm{H}_{2} \mathrm{O}+\mathrm{HCl} \\
& \text { Molar ratio }=1: 2.5 \\
& \text { - } \text { Mass ratio }=1: 1.3
\end{aligned}
$$

on the third criterion, the balance between contaminant mass and oxygen supply. For this reason, the presence/absence and the apparent supply of dissolved oxygen should also be key natural attenuation diagnostics for chloroethene-contaminated groundwater.

In sharp contrast to petroleum hydrocarbon plumes, however, DCE and VC typically are observed at $\mu \mathrm{g} / \mathrm{L}$ concentrations, when present as the result of in situ reductive dechlorination. VC concentrations, in particular, are often less than $100 \mu \mathrm{g} / \mathrm{L}$. Stoichiometric considerations dictate that a correspondingly small mass of oxygen may support substantial remediation of DCE and VC in such dilute plumes. Only $1.3 \mu \mathrm{g} / \mathrm{L}$ of oxygen is required to mineralize $1 \mu \mathrm{g} / \mathrm{L}$ of VC. Given the substantial impact that even low levels of dissolved oxygen may potentially have on DCE and VC mineralization (with respect to rates and products) the potential contribution 
of aerobic biodegradation cannot be dismissed without indisputable evidence that oxygen is absent.

Substantial mineralization of DCE and VC has been linked to oxygen, at dissolved concentrations below the $0.1-0.5 \mathrm{mg} / \mathrm{L}$ field standard for anoxic conditions (Gossett 2010; Bradley and Chapelle 2011). Thus, the fact that dissolved oxygen falls below the existing field standard is not sufficient grounds for dismissing aerobic biodegradation of DCE or VC. Likewise, ongoing $\mathrm{NO}_{3}-$, Mn- or Fe-reduction indicate that dissolved oxygen concentrations are low enough to allow electron-donor competition by anaerobes, but because these processes occur under relatively oxidized conditions they do not preclude concurrent aerobic biodegradation. In contrast, under the highly reducing conditions associated with $\mathrm{SO}_{4}$-reduction or methanogenesis, aerobic metabolism may reasonably be considered insignificant.

\section{Proposed Framework for Chloroethene Natural Attenuation Redox Interpretation}

Because mischaracterization of operant contaminant biodegradation processes can lead to adoption of expensive and ineffective remedial actions, a modified framework for assessing the role and potential importance of oxygen to chloroethene biodegradation is needed (Figure 7).

Biodegradation is considered insignificant if the observed attenuation of the parent contaminants, PCE and TCE, can be reasonably attributed to conservative processes like dilution and dispersion (i.e., if no change in total contaminant mass flux is observed). A number of environmental factors may lead to insignificant contaminant biodegradation. For example, under oxic conditions (i.e., DO greater than $0.1-0.5 \mathrm{mg} / \mathrm{L}$ field standard), bio-recalcitrance may result from oxygen inhibition of chlororespiration and poor co-substrate availability for aerobic co-metabolism. Likewise, electron donor limitation and low chlororespiration population size are just two of the factors that can constrain contaminant reductive dechlorination under anoxic conditions.

A diagnosis of "Consistent with Biodegradation" is appropriate, if attenuation of PCE and TCE cannot be attributed reasonably to abiotic processes like dilution and dispersion (i.e., if a significant downgradient decrease in total contaminant mass flux is observed). The complete parent to reductive dechlorination product mass balance leading to diagnosis 2 indicates that chlororespiration is the dominant contaminant degradation mechanism in situ. Dissolved $\mathrm{H}_{2}$ concentrations greater than $0.1 \mathrm{nM}$ are consistent with chlororespiration (Löffler et al. 1999). Geochemical indications

\section{Diagnoses}

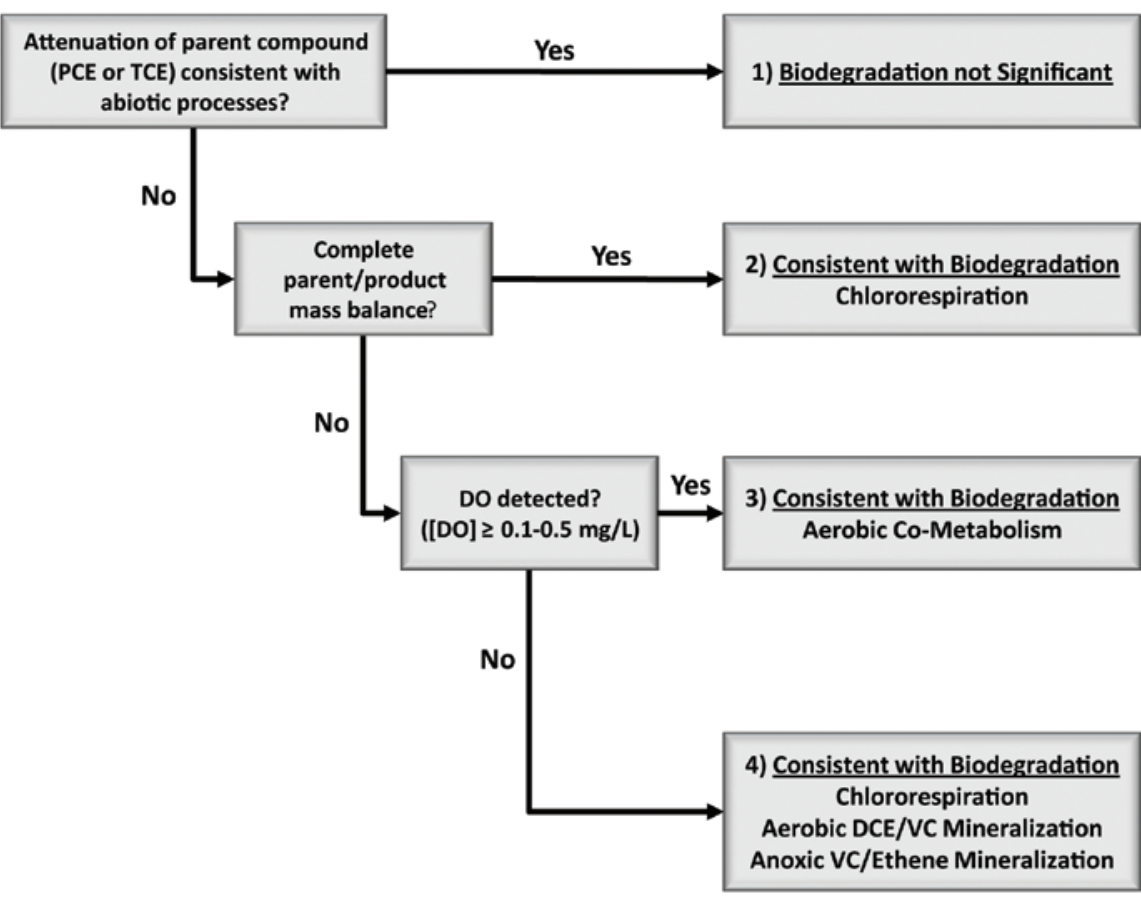

Additional Evidence and Associated Interpretations

- Many potential causes (high DO, electron donor limitation, chlororespiring population limited or absent, etc. )

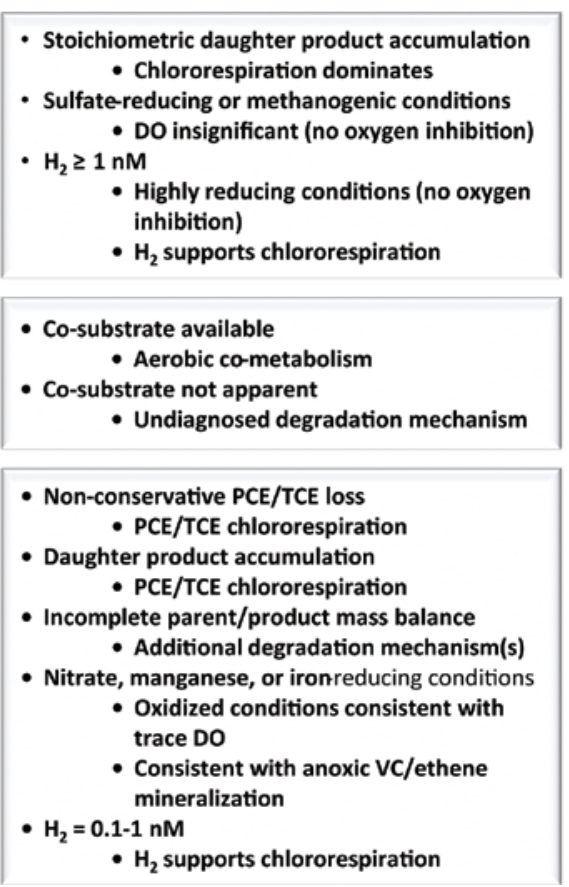

Figure 7. Modified framework for assessing mechanisms of chloroethene natural attenuation in groundwater, including the potential role of aerobic mineralization in the absence of detectable dissolved oxygen. 
of highly reducing $\mathrm{SO}_{4}$-reducing or methanogenic conditions (i.e., decreasing $\mathrm{SO}_{4}$ concentrations, increasing methane concentration, and dissolved $\mathrm{H}_{2}$ concentrations greater than or equal to $1 \mathrm{nM}$ along the groundwater flow-path) are also consistent with this conclusion and provide compelling evidence that dissolved oxygen and oxygen-based degradation mechanisms are not significant.

Diagnoses 3 and 4 cover plumes or plume locations at which attenuation of PCE and TCE cannot be attributed reasonably to abiotic processes like dilution and dispersion and an incomplete parent to reductive dechlorination product mass balance indicates that reductive dechlorination is not the only contaminant degradation mechanism occurring in situ. Under nominally oxic conditions (i.e., DO greater than $0.1-0.5 \mathrm{mg} / \mathrm{L}$ field standard), aerobic co-metabolism can lead to nonconservative loss of PCE and/or TCE along the groundwater flow-path, if a suitable co-metabolic co-substrate is available (Figure 7; diagnosis 4). Chlororespiration is not expected to be significant due to competitive and non-competitive oxygen inhibition. Under nominally anoxic conditions (i.e. DO less than $0.1-0.5 \mathrm{mg} / \mathrm{L}$ field standard), the presence of reduced daughter products along the groundwater flow-path would confirm chlororespiration (Figure 2; diagnosis 4). A parent to reductive dechlorination product imbalance is consistent with anoxic mineralization of $\mathrm{VC}$ or ethene, as previously suggested (Bradley and Chapelle, 1997, 1998a, 1998b), or with aerobic mineralization at oxygen concentrations below the field standard (Gossett 2010; Bradley and Chapelle 2011). Additional geochemical indicators may be employed to determine if oxygen-based mineralization processes contribute to the observed imbalance. Dissolved $\mathrm{H}_{2}$ concentrations below 1 $\mathrm{nM}$ are consistent with relatively oxidized $\mathrm{NO}_{3^{-}}, \mathrm{Mn}-$ and $\mathrm{Fe}-$ reducing conditions, as are accumulation of dissolved $\mathrm{Mn}$ (II) and $\mathrm{Fe}(\mathrm{II})$. As noted, ongoing $\mathrm{NO}_{3}-$, $\mathrm{Mn}$ - or Fe-reduction indicate that dissolved oxygen concentrations are limiting, but because these processes occur under relatively oxidized conditions they do not preclude aerobic biodegradation.

Reprinted from Ground Water Monitoring \& Remediation with permission of the National Ground Water Association.

The definitive version of this article is available at www.Blackwell-Synergy.com

\section{Selected References}

Adrian, L., S.K. Hansen, J.M. Fung, H. Gorisch, and S.H. Zinder. 2007. Growth of Dehalococcoides strains with chlorophenols as electron acceptors. Environmental Science \& Technology 41: 2318-2323.

Amos, B.K., K.M. Ritalahti, C. Cruz-Garcia, E. Padilla-Crespo, and F.E. Loeffler. 2008. Oxygen effect on Dehalococcoides viability and biomarker quantification. Environmental Science \& Technology 42: 5718-5726.
Barcelona, M.J. 1994. Site characterization: What should we measure, where (when?), and why? In Symposium on Intrinsic Bioremediation of Ground Water, 1-9. EPA/54Q/R-94/515. Cincinnati, Ohio: U.S. Environmental Protection Agency, National Risk Management Research Laboratory.

Bowien, B., and H.G. Schlegel. 1981. Physiology and biochemistry of aerobic hydrogen-oxidizing bacteria. Annual Review of Microbiology 35: 405-452.

Bradley, P., and F. Chapelle. 2011. Microbial mineralization of dichloroethene and vinyl chloride under hypoxic conditions. Ground Water Monitoring and Remediation. In Press.

Bradley, P.M. 2003. History and ecology of chloroethene biodegradation: A review. Bioremediation Journal 7: 81-109.

Bradley, P.M., and F.H. Chapelle. 1998a. Microbial mineralization of $\mathrm{VC}$ and DCE under different terminal electron accepting conditions. Anaerobe 4: 81-87.

Bradley, P.M., and F.H. Chapelle. 1998b. Effect of contaminant concentration on aerobic microbial mineralization of DCE and VC in stream-bed sediments. Environmental Science \& Technology 32: 553-557.

Bradley, P.M., and F.H. Chapelle. 1997. Kinetics of DCE and $\mathrm{VC}$ mineralization under methanogenic and $\mathrm{Fe}(\mathrm{III})$-reducing conditions. Environmental Science \& Technology 31: 2692-2696.

Chapelle, F.H. 1996. Identifying redox conditions that favor the natural attenuation of chlorinated èthenes in contaminated ground-water systems. In Symposium on Natural Attenuation of Chlorinated Organics in Ground Water, 17-20. EPA/540/R-96/509. Cincinnati, Ohio: U.S. Environmental Protection Agency, National Risk Management Research Laboratory.

Chapelle, F.H., J.E. Landmeyer, and P.M. Bradley. 2002. Identifying the distribution of terminal electron-accepting processes (TEAPS) in groundwater systems. In Workshop on Monitoring Oxidation-Reduction Processes for GroundWater Restoration, 5-17. EPA/600/R-02/002. Cincinnati, Ohio: U.S. Environmental Protection Agency, National Risk Management Research Laboratory.

Chapelle, F.H., J.E. Landmeyer, and P.M. Bradley. 1996. Assessment of intrinsic bioremediation of jet fuel contamination in a shallow aquifer, Beaufort, South Carolina. U.S. Geological Survey Water Resources Investigations Report 95-4262, 30.

Chapelle, F.H., P.M. McMahon, N.M. Dubrovsky, R.F. Fujii, E.T. Oaksford, and D.A. Vroblesky. 1995. Deducing the distribution of terminal electron-accepting processes in hydrologically diverse groundwater systems. Water Resources Research 31: 359-371. 
Friedrich, B., and E. Schwartz. 1993. Molecular biology of hydrogen utilization in aerobic chemolithotrophs. Annual Review of Microbiology 47: 351-383.

Gossett, J.M. 2010. Sustained aerobic oxidation of vinyl chloride at low oxygen concentrations. Environmental Science \& Technology 44, no. 4: 1405-1411.

He, J., K.M. Ritalahti, M.R. Aiello, and F.E. Loffler. 2003. Complete detoxification of vinyl chloride by an anaerobic enrichment culture and identification of the reductively dechlorinating population as a Dehalococcoides species. Applied and Environmental Microbiology 69: 996-1003.

Kampbell, D.H., and F.H. Chapelle. 2002. Session 5 summary: Measurement of dissolved gases. In Workshop on Monitoring Oxidation-Reduction Processes for Ground-Water Restoration, 101-103. EPA/600/R-02/002. Cincinnati, Ohio: U.S. Environmental Protection Agency, National Risk Management Research Laboratory.

Löffler, F.E., J.M. Tiedje, and R.A. Sanford. 1999. Fraction of electrons consumed in electron acceptor reduction and hydrogen thresholds as indicators of halorespiratory physiology. Applied and Environmental Microbiology 65: 4049-4056.

Vogel, T.M. 1994. Natural bioremediation of chlorinated solvents. In Handbook of Bioremediation, ed. Norris, R.D., R.E. Hinchee, R. Brown, P.L. McCarty, L. Semprini, J.T. Wilson, D.H. Kampbell, M. Reinhard, E.J. Bouwer, R.C. Borden, T.M. Vogel, J.M. Thomas, and C.H. Ward, 201225. Boca Raton, Florida: Lewis Publishers.

Vogel, T.M., C.S. Criddle, and P.L. McCarty. 1987. Transformation of halogenated aliphatic compounds. Environmental Science \& Technology 21: 722-736.

Wiedemeier, T.H., H.S. Rifai, C.J. Newell, and J.T. Wilson. 1999a. Evaluating natural attenuation, Chapter 7. In Natural Attenuation of Fuels and Chlorinated Solvents in the Subsurface, 298-360. New York: John Wiley and Sons.
Wiedemeier, T.H., H.S. Rifai, C.J. Newell, and J.T. Wilson. 1999b. Intrinsic bioremediation of petroleum hydrocarbons, Chapter 5. In Natural Attenuation of Fuels and Chlorinated Solvents in the Subsurface, 189-240. New York: John Wiley and Sons.

Wiedemeier, T.H., H.S. Rifai, C.J. Newell, and J.T. Wilson. 1999c. Intrinsic bioremediation of chlorinated contaminants, Chapter 6. In Natural Attenuation of Fuels and Chlorinated Solvents in the Subsurface, 241-297. New York: John Wiley and Sons.

Wiedemeier, T.H., M.A. Swanson, D.E. Moutoux, E.K. Gordon, J.T. Wilson, B.H. Wilson, D.H. Kampbell, P.E. Haas, R.N. Miller, J.E. Hansen, and F.H. Chapelle. 1998. Technical protocol for evaluating natural attenuation of chlorinated solvents in groundwater, 128p. EPA/600/R-98/128. Washington, DC: U.S. EPA.

Wiedemeier, T.H., J.T. Wilson, D.H. Kampbell, R.N. Miller, and J.E. Hansen. 1994. Draft technical protocol for implementing intrinsic remediation with long-term monitoring for natural attenuation of fuel contamination dissolved in groundwater, 323p. San Antonio, Texas: U.S. Air Force Center for Environmental Excellence.

Wilkin, R.T., and C.J. Ptacek. 2002. Session 4 summary: Field measurement of geochemical Redox Parameters, 89-99. In Workshop on Monitoring Oxidation-Reduction Processes for Ground-Water Restoration. EPA/600/R-02/002. Cincinnati, Ohio: U.S. Environmental Protection Agency, National Risk Management Research Laboratory.

Biographical Sketches

Paul M. Bradley, PhD, corresponding author, is a research ecologist at the USGS South Carolina Water Science Center, U.S. Geological Survey, 720 Gracern Rd, Suite 129, Columbia, SC 29210; pbradley@usgs.gov. 


\section{Appendix 1. Project Publications}

Bradley, P.M., 2007, Dichloroethene and vinyl chloride degradation potential in wetland sediments at Twin Lakes and Pen Branch, Savannah River National Laboratory, South Carolina: U.S. Geological Survey Open-File Report 2007-1028, 21 p. (Also available online at http://pubs.usgs. gov/of/2007/1028)

Bradley, P.M., 2008, Potential for microbial degradation of cis-dichloroethene and vinyl chloride in streambed sediment at the U.S. Department of Energy, Kansas City Plant, Missouri: U.S. Geological Survey Scientific Investigations Report 2009-5137, 12 p. (Also available online at $h t t p: / /$ pubs.usgs.gov/of/2009/5137)

Bradley, P.M., 2011, Reinterpreting the importance of oxygenbased biodegradation in chloroethene-contaminated groundwater: Groundwater Monitoring and Remediation, v. 31, no. 4, p. 50-55. In Press.

Bradley, P.M., and Chapelle., F.H., 2007, Accumulation of dechlorination daughter products: A valid metric of chloroethene biodegradation?: Remediation Journal, v. 17, no. 4, p. 7-22.

Bradley, P.M., and Chapelle, F.H., 2010, Biodegradation of chlorinated ethenes, chap. 3 of Stroo, H.F., and Ward, C.H., eds., In Situ Remediation of Chlorinated Solvent Plumes: New York, Springer, p. 39-67..

Bradley, P.M., and Chapelle, F.H., 2011, Microbial mineralization of dichloroethene and vinyl chloride under hypoxic conditions: Groundwater Monitoring and Remediation, v. 31 , no. 4 , p. $39-49$.
Bradley, P.M., Chapelle, F.H., and Löffler, F.E., 2008, Anoxic mineralization: Environmental reality or experimental artifact?: Ground Water Monitoring and Remediation, v. 28, no. 1 , p. 47-49.

Bradley, P.M., Lacombe, P., Imbrigiotta, T., Chapelle, F.H., and Goode, D.J., 2009 Flowpath-independent monitoring of reductive dechlorination in a fracture rock aquifer: Groundwater Monitoring and Remediation, v. 29, no. 4, p. 46-55.

Bradley, P.M., Singletary, M.A., and Chapelle, F.H., 2007, Chloroethene dechlorination in acidic groundwater: Implications for combining Fenton's Treatment with natural attenuation: Remediation Journal, v. 18, no. 1, p 7-v19.

Chapelle, F.H., and Bradley, P.M., 2007, Hydrologic significance of carbon monoxide concentrations in ground water: Ground Water, v. 45, no. 3, p. 272-280.

Chapelle, F.H., Bradley, P.M., Goode, D.J., Tiedeman, C., Lacombe, P.J., Kaiser, K., and Benner, R., 2009, Biochemical indicators for the bioavailability of organic carbon in ground water: Ground Water, v. 47, no. 1, p. 108-121.

Chapelle, F.H., Bradley, P.M., McMahon, P.B., and Lindsey, B.D., 2009, What does "Water Quality" mean?: Ground Water, v. 47 , no. 6 , p. 752-754.

Chapelle, F.H., Bradley, P.M., Thomas, M.A., and McMahon, P.B., 2009, Distinguishing iron-reducing from sulfatereducing conditions: Ground Water, v. 47, no. 2, p. 300-305.

Vroblesky, D.A., F.H. Chapelle, and P.M. Bradley. 2007. A simple pore-water hydrogen diffusion syringe sampler. Ground Water, v. 45, 6, p. 798-802. 
Prepared by:

USGS Publishing Network

Raleigh Publishing Service Center

3916 Sunset Ridge Road

Raleigh, NC 27607

For additional information regarding this publication, contact:

USGS South Carolina Water Science Center

Stephenson Center, Suite 129

720 Gracern Road

Columbia, SC 29210-7651

(803) 750-6100

Or visit the USGS South Carolina Water Science

Center Web site at:

http://sc.water.usgs.gov 



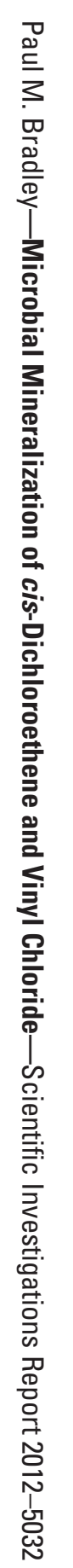

